\title{
A new specimen of the basal macronarian Camarasaurus (Dinosauria: Sauropoda) highlights variability and cranial allometry within the genus
}

\author{
D. Cary WOODRUFF ${ }^{1,2}$, D. Ray WILHITE ${ }^{3}$, Peter L. LARSON ${ }^{4}$, Matthew EADS ${ }^{5}$
}

Key words: Camarasaurus, cranial allometry, Morrison Formation.

\begin{abstract}
Camarasaurus represents one of the most common dinosaurs from North America, and certainly a contender for one of the most abundantly represented dinosaur taxa worldwide. With numerous specimens ranging the gamut of completeness and maturity, Camarasaurus would theoretically represent a neosauropodian exemplar towards better understanding intra- and interspecific variation, dimorphism, and life history development and strategies. And yet, counterintuitively, its abundance is seemingly a deterrent for active research. Herein we describe a new specimen of Camarasaurus sp. which is most notably known from a nearly complete and articulated skull. While Camarasaurus cranial material is unquestionably the most common sauropod cranial material from North America, our understanding of the total cranial morphology is limited, and largely relies on more limited and historic specimens. In addition to further illuminating the morphology and variation present in Camarasaurus crania, associated post-crania also allow for the first recognition of possible cranial allometry. The identification of this perplexing cranial allometry in several specimens indicates that it is not a singular variation. Though this analysis was not able to source the causal mechanism, factors such as taxonomy, dimorphism, or extreme intra-/intraspecific variation are all possible considerations for future analyses. The recognition of this undocumented cranial allometry further emphasizes that despite being so numerous, there is still vast gaps in our knowledge about Camarasaurus; and this analysis further echoes that the genus is in desperate need of revision.
\end{abstract}

\section{INTRODUCTION}

The macronarian sauropod Camarasaurus is probably the most abundant dinosaur fossil recovered from the Late $\mathrm{Ju}$ rassic Morrison Formation of western North America. With potentially four species comprising the genus $(C$. lentus, C. grandis, C. supremus, and C. lewisi), over 175 specimens are archived in museums to-date (Foster, 2001). While recorded from the northern extent of the Morrison Formation (Woodruff, Foster, 2017), such northernly specimens are not as well documented as their more southerly counterparts (such as the famed specimens from Dinosaur National Monument, Utah, or Como Bluff, Wyoming [both in the U.S.A.]).

\footnotetext{
${ }^{1}$ Royal Ontario Museum, University of Toronto, 100 Queens Park, Toronto, ON M5S 2C6, Canada; sauropod4@gmail.com.

${ }^{2}$ Great Plains Dinosaur Museum, 405 North 1st St East, PO Box 170 Malta, 59538 Montana, U.S.A.

${ }^{3}$ College of Veterinary Medicine, Auburn University, Auburn, Alabama 36849, U.S.A.; drw0004@auburn.edu.

${ }^{4}$ Black Hills Institute of Geological Research, Inc., 117 Main Street, Hill City, South Dakota 57745, U.S.A.; peterl@bhigr.com.

${ }^{5}$ Department of Geosciences, Fort Hays State University, 600 Park Street, Tomanek Hall 233, Kansas 67601, U.S.A.; matthewseads@gmail.com.
} 
Recent research has suggested that the northern extent of the Morrison Formation environmentally differed from the coeval southern regions, and that this difference harbored environmentally restricted genera and species (Maidment $e t$ al., 2018; Woodruff et al., 2018, 2019; Maidment, Muxworthy, 2019). The role Camarasaurus played in this environmental/latitudinal hypothesis remains uncertain. Recently, two relatively small-statured Camarasaurus specimens, one from north central Wyoming (Waskow, Sander, 2014) and the other from central Montana (Woodruff, Foster, 2017), were reported. While the small-stature of one of these specimens was initially used as a maturational indicator (see Woodruff, Foster, 2017), histologic analysis of both revealed that they were in fact, histologically among the most mature dinosaur specimens assessed to-date (Waskow, Sander, 2014; Woodruff, Foster, 2017). Therefore, the relative size of these two specimens could not unequivocally contribute to this ongoing hypothesis.

However, here we report on a new Camarasaurus specimen from northeastern Wyoming. This specimen is larger than the two aforementioned specimens, and contributes to our further understanding of the degrees of size-related skeletal plasticity and intraspecific variation within the genus. Furthermore, the slight offset of many of the cranial elements allows for a detailed element-based comparison.

\section{MATERIAL AND METHODS}

No permits were required for the described study. The specimen was macroscopically examined first hand and documented following standard photographing and measuring techniques and devices (i.e., digital calipers). For measurements beyond the capabilities of traditional calipers, a Bosch ${ }^{\mathrm{TM}}$ GLM 15 Compact Laser Measure was used, in accordance with the guidelines and procedures outlined in Woodruff, Foster (2017). For specimens used in the geometric morphometric analysis, measurements used herein were either sourced from the previous literature, or if no measurements were given, calculated in ImageJ.

The specimen, BHI 6200, was collected near the town of Hulett, in Crook County, Wyoming, U.S.A., and is accessioned into the permanent collections of the Black Hills Institute of Geological Research, Inc. This specimen is available for examination and study for all academics and qualified researchers. Additionally, research grade casts are accessioned in other institutions - including the Great Plains Dinosaur Museum and Auburn University - and likewise available for study; and a photogrammetric model is digitally reposited on MorphoSource (Specimen ID: 000393274; https://www.morphosource.org/concern/biological_specimens/000393274).

\section{D GEOMETRIC MORPHOMETRICS}

Landmark-based geometric morphometrics (GM) retains the spatial ordination of a structure - allowing for a more detailed assessment of the total spatial geometry. Using homologous points, whether in two- or three-dimensional space (2D and 3D), allows for the construction of orthogonal transformations reflecting the degree of variance amongst structures (a.k.a. principal component analysis; PCA). While 2D GM is the more common in dinosaur paleontology, this dimensional analysis only reflects a single anatomical orientation at a time (i.e., lateral, dorsal, etc.). Additionally, 2D analyses - regardless of the orientation - compress spatial data (especially the Z-axis); which can be problematic for highly 3D structures, like skulls.

If the goal is to capture and maintain the most precise spatial geometry, then $3 \mathrm{D}$ GM is the more accurate methodology (Gunz, Mitteroecker, 2013; Hedrick, Dodson, 2013; Cooney et al., 2017; Buser et al., 2018; Lefebvre et al., 2020; Woodruff et al., 2021). For this analysis, 2D GM was conducted on lateral views of Camarasaurus skulls. 2D GM was conducted primarily because it was not feasible within the scope and duration of this project to 3D model each skull in the analysis. While 3D is the accurate methodology, 2D analyses can still produce results which can be supported and even substantiated by 3D (Gunz, Mitteroecker, 2013; Hedrick, Dodson, 2013; Cooney et al., 2017; Buser et al., 2018; Lefebvre et al., 2020; Woodruff et al., 2021).

For 2D GM, photographs of 10 Camarasaurus skull were positioned (or reflected) in left lateral orientation, and 46 homologous Type I and Type II landmarks were placed on each image (Fig. 1). The landmarked images were uploaded in the statistical computing program Comprehensive $\mathrm{R}$ Archive Network, CRAN version 3.3.2, and the PCA were constructed using the GM shape analysis package geomorph (Adams, Otárola-Castillo, 2013). Missing landmarks were examined in two ways: 1) an estimation function was applied, and 2) missing landmarks were culled for all specimens. To assess for possible allometry, the first two PC axes were correlated with the $\log 10$ of skull length, a proxy of size. One specimen, YPM 1905 was excluded from the GM analysis because so much of the skull is highly speculative and reconstructed; but this specimen was used in additional analyses (such as skull:femur ratio; see below).

\section{PHOTOGRAMMETRY, 3D RECONSTRUCTION, AND 3D MODELING OF BHI 6200}

The 3D model of BHI 6200 was constructed via photogrammetry following the techniques and procedure outlined in Falkingham (2012) and Mallison, Wings (2014) using the pho- 


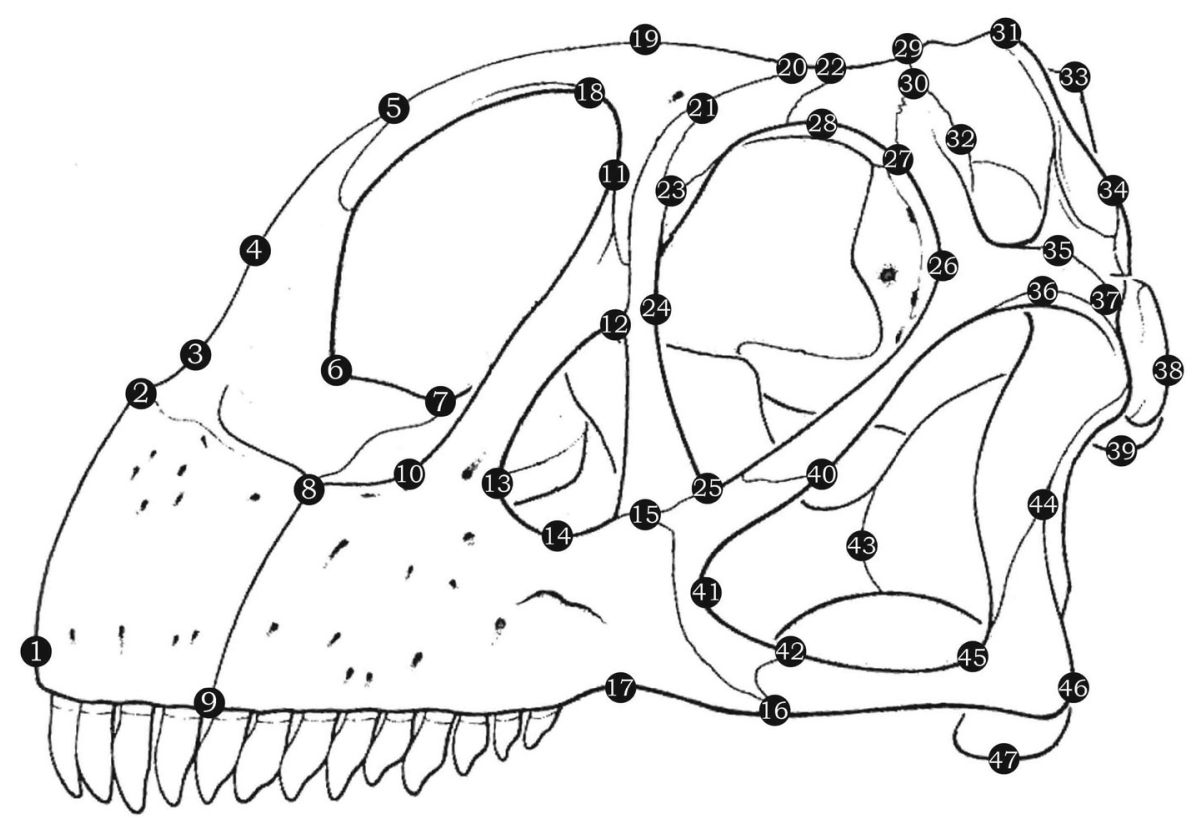

Fig. 1. Type 1 and Type 2 2D landmark positions used in the GM analysis. Camarasaurus lentus (CM 11338) diagram from Sereno, Wilson (2005)

togrammetric processing software Agisoft PhotoScan ${ }^{\mathrm{TM}}$ version 1.2.6 build 2834. Autodesk Meshmixer ${ }^{\mathrm{TM}}$ version 3.5 was used to construct a 'watertight' backing for the 3D model. The photogrammetrically constructed 3D model of BHI 6200 represents a surface scan from largely a single orientation. While there are many benefits to hand-held scanning and photogrammetry, these techniques may not capture full 3D details. In incomplete renderings, such as BHI 6200, it leaves a micron thick 'skin' that needs to be sealed and closed prior to printing. For this purpose, and given the size of the skull, our goal would be to print using fused deposition modeling (FDM) which uses filament plastic deposited on a cartesian plane.

Due to the skull still being embedded in the field jacket, a complete 3D rendering was unable to be completed. In order to give an approximation of what the entire skull would look like prepared, the skull was digitally manipulated in Autodesk Meshmixer 3.5. The .obj file was imported and using the 'mirror tool', and from there, elements can be mirrored and joined together. In order to successfully mirror an object at least $50 \%$ of the object must be present an order to give overlap. Unfortunately, BHI 6200 has at most 35\% of the skull prepped in the field jacket. With less than $50 \%$ of an object, polygons must be added and sculpted to fill in gaps. While unable to recreate an entire digital representation of the skull of BHI 6200, there is sufficient overlap to create a plaque mount of the skull. Polygons were used to artificially create the back of the skull in order to produce a "watertight" model that can be successfully $3 \mathrm{D}$ printed.

\section{THE BENEFITS OF DIGITAL RETRODEFORMATION}

It is true that retrodeformation, in any form, is a hypothetical transformation to the supposed original state. While the scientific accuracy and legitimacy of retrodeformation has been questioned over the years (Taylor et al., 2009), this analysis finds the merits and ultimate goals of retrodeformation to far outweigh any potential negatives. As mentioned extensively in the literature, taphonomic processes can distort not only the element in question, but warp our assessment of its morphology (Arbour, Currie, 2012; Tschopp et al., 2013; Benazzi et al., 2014; Tallman et al., 2014; Cuff, Rayfield, 2015; Müller et al., 2018; Schlager et al., 2018); and extensively we are left to speculate on the element's original condition - which in and of itself is a hypothetical inference on morphology.

However, this analysis copiously agrees that any form of retrodeformation must be done in the most scientific manners available. The extensive need and application of retrodeformation additionally highlights yet another benefit of 3D modeling in vertebrate paleontology. At its simplest level, missing sides or elements can be mirrored and mated to create a composite. Digital corrections such as this can produce what could be argued to be a more natural reflection of the undistorted morphology.

An added benefit of digital retrodeformation can be its application towards GM. As mentioned above, the point of GM is to retain the spatial geometry of a structure. GM on 
non-retrodeformed elements is simultaneous capturing the ordination of the osteology and the taphonomy. In regards to Camarasaurus, as Woodruff, Foster (2017) noted for GPDM 220 , much of this specimen's 'aberrant' morphology could simply be attributed to dorsoventral taphonomic distortion. And, as the 2D GM analysis here reveals, such distortion can exclude landmarks, and has the potential to allow for more 'natural' shape comparisons. Finally, like the benefits of mirroring and creating a composite skull, digital retrodeformation has the potential to allow for 3D GM analyses on fossils that was previously not possible.

\section{SYSTEMATIC PALEONTOLOGY}

Sauropoda Marsh, 1878

Macronaria Wilson and Sereno, 1998

Camarasaurus Cope, 1877

Camarasaurus sp.

We identify BHI 6200 as belonging to the basal macronarian genus Camarasaurus, based on the overall proportions of the skull, including: the dorsoventrally heightened, box-like skull, the vaulted narial region, and the spatulate teeth clearly distinguish this specimen as a non-diplodocid neosauropod. Unlike the second Morrison Formation macronarian, Brachiosaurus altithorax, the box-like skull of BHI 2600 is less elongate and lacks the strikingly abrupt and dorsally heighted narial region.

Referred Specimen: BHI 2600, a nearly complete specimen consisting of cranial, axial, and appendicular elements found in near articulation.

\section{INSTITUTIONAL ABBREVIATIONS}

AMNH - American Museum of Natural History, New York, NY, U.S.A.; BHI - Black Hills Institute of Geological Research, Hill City, SD, U.S.A.; BYU - Brigham Young University Museum of Paleontology, Provo, UT, U.S.A.; CM - Carnegie Museum of Natural History, Pittsburgh, PA, U.S.A.; DINO - Dinosaur National Monument, Vernal, UT, U.S.A.; FPDM - Fukui Prefectural Dinosaur Museum, Katsuyama, Japan; GMNH - Gunma Museum of Natural History, Tomioka, Japan; GPDM - Great Plains Dinosaur Museum, Malta, MT, U.S.A.; KUVP - University of Kansas Natural History Museum, Lawrence, KS, U.S.A.; MWC Museum of Western Colorado, Fruita, CO, U.S.A.; OMNH Sam Noble Oklahoma Museum of Natural History, Norman, OK, U.S.A.; SDSM - South Dakota School of Mines and
Technology, Rapid City, SD, U.S.A.; SMA - Sauriermuseum Aathal, Aathal, Switzerland; USNM - United States National Museum, Washington, D.C., U.S.A; UUVP - Natural History Museum of Utah, Salt Lake City, UT, U.S.A.; WDC Wyoming Dinosaur Center, Thermopolis, WY, U.S.A.; YPM - Yale Peabody Museum of Natural History, New Haven, CT, U.S.A.

\section{DESCRIPTION}

This specimen, affectionately referred to as "Elaine" in honor of the landowner, Mrs. Elaine Waugh, was collected starting in 1999 from Crook County, Wyoming. As of this publication, only the skull and right femur have been partially prepared. Both still remain in their field jackets, and as such, the opposing sides are not visible for study. For the purposes of this publication, only the elements (and their orientations) visible will be described.

\section{CRANIAL}

The completeness, articulation, and size of BHI 6200 make it a truly impressive specimen. While it underwent some taphonomic distortion, most of the cranial elements are only slightly offset from their adjoining articulation surfaces, allowing for detailed examination and morphologic assessments and comparisons. The specimen still resides in the original field jacket with the left side prepared (Fig. 2). Portions of some right elements can be observed (such as the right premaxilla and portions of the braincase), but unless explicitly stated, all elemental descriptions below are for left elements.

Premaxilla. The premaxilla of BHI 6200 exhibits the 'typical' Camarasaurus condition; the main portion of the premaxilla is rectangular in shape - being dorsoventrally taller than anteroposteriorly elongate (such as AMNH 467, CM 1138, DINO 28, DINO 975, GMNH-PV 101, GPDM 220, SDSM 114501, USNM V 13786; Madsen et al. [1995]; Woodruff, Foster, 2017; Fig. 2). A few small foramina are dispersed across the distal region of the premaxilla, and none are particularly sizable nor are they distinctly arranged or cluster on the element. The sutural contact with the maxilla appears to be a fairly straight, slightly posteriorly oriented line. Interestingly, the premaxilla appears to contain two alveoli, with two, fully erupted teeth. This premaxillary tooth count of two differs from other Camarasaurus specimens such as GPDM 220 with a premaxillary tooth count of four.

As in other Camarasaurus, the bulbous nasal process is dorsoventrally elongate, and tapers as it projects posteriorly. Though the nasal and frontal contact is missing, the naris of 


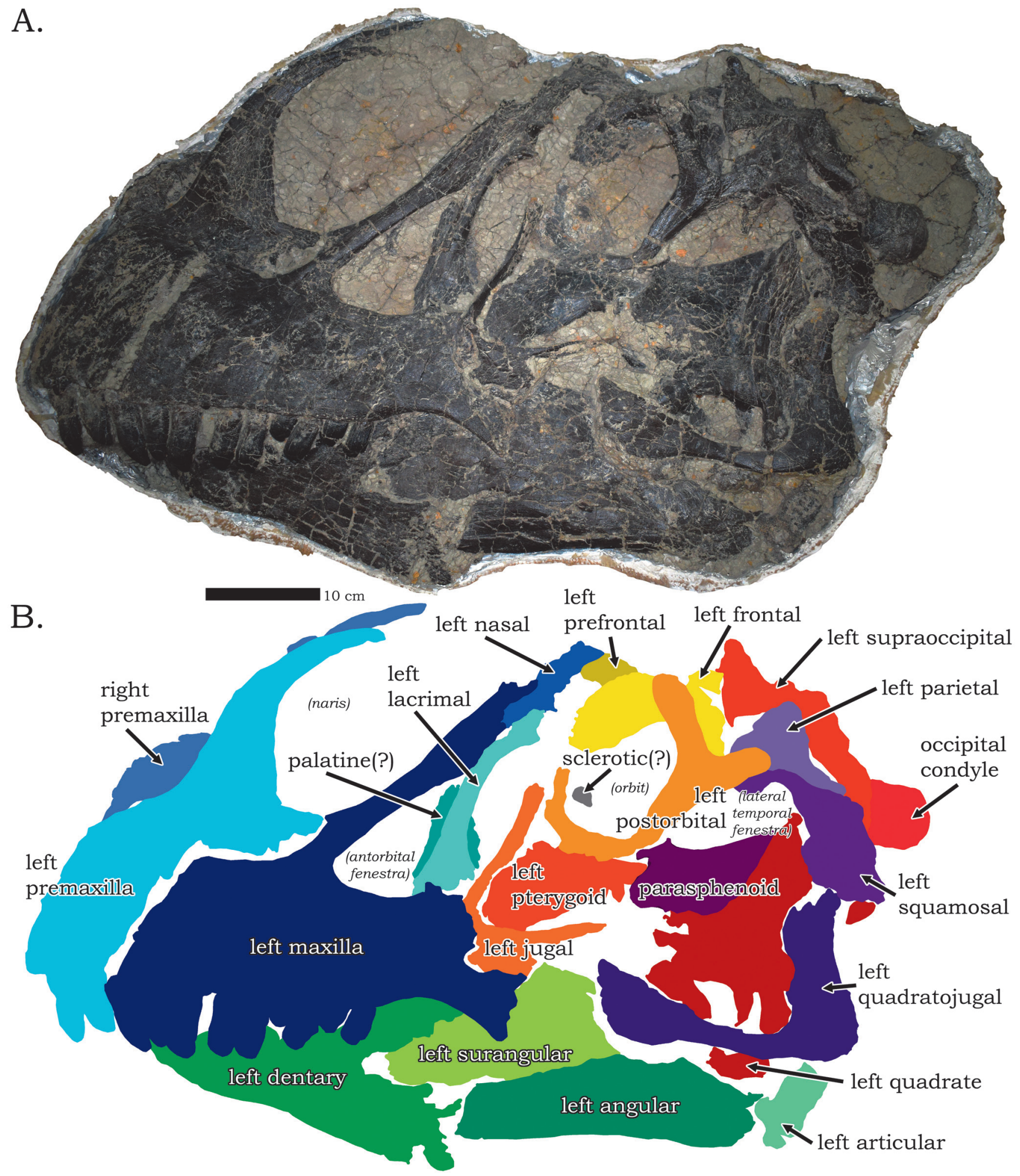

Fig. 2. The skull of BHI 6200 (A), with corresponding element identification (B). A and B to scale. Scale bare $=10 \mathrm{~cm}$ 
BHI 6200 would appear to be ovoid (dorsoventally taller than anteroposteriorly elongate) as in other Camarasaurus specimens. In BHI 6200, there is a short anteroposterior distance from the anterior most region of the premaxilla to the nasal process. This 'snout length' is highly variable in Camarasaurus, with 'short-' (AMNH 467, CM 11338, GMNH-PV 101, YPM 1905), 'mid-' (DINO 28, DINO 975, SMA 0002, USNM PAL 369928), and 'long-snouts' (DINO 2580, GPDM 220, USNM V 13786) each occurring with similar frequency. The inflection of the dorsal curvature from the anterior portion of the premaxilla to the nasal process also varies within Camarasaurus; in BHI 6200, this profile is more of a curve, opposed to a 'stepped' process.

Maxilla. The maxilla is exquisitely preserved (Fig. 2). In overall profile, the body of the maxilla is rectangular in profile (anteroposteriorly longer than dorsoventrally tall). As Woodruff, Foster (2017) noted, the maxillary shape of Camarasaurus appears to be either rectangular (DINO 28, GPDM 220, SMA 0002, and USNM V 13786) or squared (CM 11338, DINO 975, and YPM 1905). The anterior portion of the maxilla, specifically the area just posterior to the premaxilla-maxilla contact is the dorsoventrally tallest region of the element. Aside from the angle articular contact, the area is fairly uniform in dorsoventral height. Anteriorly to posteriorly, the maxillary body is posteriorly tapered $14.2 \mathrm{~cm}$ at the premaxilla-maxilla contact to $9.04 \mathrm{~cm}$ at the maxilla-jugal. The nasal process of the maxilla is anteroposteriorly elongate and fairly uniform in thickness. This process is oriented $\sim 58^{\circ}$ to the long axis of the maxilla. Ten maxillary teeth are present, and there are no toothless alveoli. Postmortem, some of the maxillary teeth may have slipped, but in general they appear to be superficially in place, with the dorsoventrally longest teeth anterior and the shortest posterior. Maxillary tooth \#4 is interesting because only the $\sim 0.5 \mathrm{~cm}$ tip of the crown is erupted. None of the immediately adjacent teeth are 'new' - all have Camarasaurus-typical wear facets - so this may indicate something happened to the previous \#4 tooth, or differential rates in individual tooth replacement.

Interestingly, as noted in GPDM 220 by Woodruff, Foster (2017), the posterior most region of the maxilla has a strong ventrally curved margin posterior to the last maxillary tooth. Many Camarasaurus specimens exhibit a curved ventral margin, but in most, this is more of a step (AMNH 467, CM 11338, DINO 28, GMNH-PV 101, USNM V 13786, and YPM 1905). SMA 0002 and DINO 975 both have a curved ventral margin much more like that of BHI 6200. However, the degree of this curvature in BHI 6200 is the strongest thus far documented.

Lacrimal. Approximately from the lacrimal through the postorbital represents the region of the skull that has undergone the most taphonomic displacement. The placement and relative location of these displaced elements will be noted in their respected descriptive sections.

The lacrimal is dorsoventrally elongate and fairly uniform throughout much of its anteroposterior thickness (Fig. 2). The widest portion of the lacrimal is the ventral region which would contact the maxilla and jugal. While the ventral region of the lacrimal is wider than the dorsal aspect, the overall lacrimal morphology is non-tapered, as in AMNH 467, DINO 28, GMNH-PV 101, GPDM 220, and YPM 1905, versus the tapered CM 11338, DINO 975, SMA 0002, and USNM V 13786. While it could just be obscured by matrix, the lacrimal of BHI 6200 seems to lack the laterally directed spur along the dorsolateral margin. This 'spur' is present in other Camarasaurus specimens, but notably absent in GPDM 220 (Woodruff, Foster, 2017).

As in all other Camarasaurus specimens, the antorbital fenestra exhibits a widened ventral border and tapers anteriorly, producing teardrop-shaped fenestra. In BHI 6200, the antorbital fenestra is dorsoventrally shorter (making it more triangular) in comparison to the 'typical' Camarasaurus condition - save one specimen, GPDM 220.

Nasal. The nasal of BHI 6200 is damaged and incomplete (Fig. 2). Only the posteriormost portion - that articulating with the prefrontal and lacrimal - remains. Though the element is damaged, there is a posterior projection that may be the same process as in CM 11338, DMN 28, GMNH-PV 101, and GPDM 220 (Woodruff, Foster, 2017).

Prefrontal. The prefrontal of BHI 6200 is a bit distorted and obscured by the surrounding elements (Fig. 2). The prefrontal is anteroposteriorly short and nearly as laterally wide, producing a squared profile. The sutural contact with the opposing prefrontal is not visible, but given the consistent morphologies, we would predict that the prefrontal of BHI 6200 likewise possesses a widened medial flange.

Frontal. Like many of the dorsal cranial elements, the frontal is damaged and displaced (Fig. 2). In lateral view, the frontal expresses the typical Camarasaurus condition in that the frontal is approximately rectangular, being anteroposteriorly longer than dorsoventrally tall. While distorted, the lateroventral margin of the frontal is intact, and its curved profile constitutes a portion of the orbits dorsal rim. Unfortunately, the obscured dorsal surface of the frontal prohibits examination and determination if it possess a frontal aperture (Woodruff, Foster, 2017).

Postorbital. The postorbital of BHI 6200 is perhaps visually, the most taphonomically deformed cranial element (Fig. 2). As is, the anterior $\sim$ half of the postorbital constitutes the ventral margin of the orbit. Additionally, the anterior most portion of the postorbital is distorted and dorsally curves to nearly contact the anterolateral corner of the frontal. If undistorted, in its natural state, we would predict that the anterior process of the postorbital would be anteroventally oriented; and with the lacrimal 
and jugal, forming the ventral margin of the orbit. This would produce what McIntosh et al. (1996a) referred to as an "inverted teardrop" orbit profile.

The posterior aspect of the postorbital, while dorsally displaced, is less taphonomically distorted. This region is Yshaped, with a dorsal process that would contact the frontal and parietal, and a posterior process that would contact the squamosal - if not displaced. Unlike GPDM 220, BHI 6200 exhibits morphology more akin to the 'typical' Camarasaurus condition. The dorsal process is fairly uniform in anteroposterior thickness, save for a slightly expanded and rounded dorsal edge. The dorsal process is also the longer of the two, being approximately 1.7 times longer than the posterior process.

Jugal. The jugal is highly distorted, and given its displacement and distortion, this likely interferes with our morphologic interpretation (Fig. 2). The jugal is dorsoventrally taller anteriorly, with a squared anterior profile, and a dorsoventrally thinned $(\sim 1 / 4$ the dorsoventral thickness) posteriorly oriented posterior process. The anterior border of the jugal is primarily in contact with the maxilla, with a smaller posterior quadratojugal contact. In BHI 6200 , there is a posterodorsally oriented process that seem rather unusual. In the 'typical' Camarasaurus condition, the jugal has a posterodorsally oriented process that articulates with the postorbital along an angled contact. In BHI 6200, this process is very elongate, anteroposteriorly thin, rather uniform in thickness; more so deviating of the 'normal' morphology (such as CM 11338). The condition of BHI 6200 is more like that of DINO 2580, and we would suggest that this 'aberrant' morphology is likely a byproduct of taphonomic displacement of the jugal and breakage and distortion of this thin process. The highly distorted posterior aspect of the postorbital (discussed above) would support this interpretation. For the time being we have left this distorted process as part of the jugal.

Quadratojugal. The quadratojugal is nicely separated and appears to have suffered little if any distortion (Fig. 2). In overall profile, the quadratojugal is L-shaped. There is an anteroposteriorly elongate process, and posteriorly there is a $\sim$ perpendicular process that is shorter in length. In regards to the anterior process, in Camarasaurus specimens, the anteriormost, jugal articulating portion can vary a bit. In some specimens, such as CM 11338, DINO 28, and UUVP 3293, this articulating process is slightly dorsoventrally expanded; while in other specimens, including DINO 975, USNM V 13786, and YPM 1905, this contact is much more dorsoventrally expanded. This corresponding region in BHI 6200 expresses the expanded condition, and in fact, significantly more so than has been reported in other Camarasaurus specimens to-date. The posterior, dorsoventrally oriented process is very rectangular in profile - being dorsoventrally taller than anteroposteriorly long. The quadratojugal is a bit dis- placed from the articulating squamosal, and we can see the posterodorsally angled and anteriorly scalloped region that would accommodate the articulating squamosal.

Quadrate. As in other Camarasaurus specimens, the quadrate of BHI 6200 is a robust element (Fig. 2). Due to taphonomic displacement, the majority of the lateral view of the quadrate is visible. In lateral view, the quadrade is vertically oriented and triangular - projects nearly as anteriorly as the element is dorsoventrally tall (approximately 79\%). Nearly the entire shaft of the quadrate is visible. As in other Camarasaurus quadrates, the shaft is mediolaterally thickened with a prominent and pronounced lateral edge traversing the dorsoventral length of the shaft. The sutural contact for the squamosal and quadratojugal is visible along the dorsoventral length of the quadrate shaft. Anterior to the shaft, is the medially thinned and concaved pterygoid process of the quadrate. The distal end (articulating with the articular) is widened and robust, as in other Camarasaurus specimens.

Parietal. Only the posterolateral aspect of the parietal can be observed, but the posteriormost region of the cranium is wonderfully preserved and the region least distorted (Fig. 2). The posterior portion of the parietal is the largest region of this element, and it is strongly rectangular in overall profile (nearly three times wider laterally than they are anteroposteriorly). Due to the taphonomic distortion - even if less pronounced in this region of the skull - the supratemporal fenestra is partially obscured. Though distorted, the fenestra does not appear to have been originally excessively large - as in GPDM 220 - and appears to have been more comparable in relative proportion to that of other specimens (such as CM 11338, UUVP 4286, or UUVP 3568). The supratemporal fenestra is slightly posterolaterally oriented, and is bordered by the frontal, parietal, and postorbital. The dorsal most aspect of the parietal is not visible, so at this time we cannot comment on the presence of sagittal nuchal crest (Woodruff, Foster, 2017).

Occipital and Paroccipital processes. Though not completely visible, the dorsal region of the occipital condyle appears to be laterally wider (Fig. 2). Coupled with the sub-horizontal dorsal margin, the occipital condyle, viewed as is, almost has a triangular profile. BHI 6200 expresses the typical Camarasaurus paroccipital process condition. As in AMNH 5761, CM 11338, DINO 28, GMNH-PV 101, GPDM 220, SMA 0002, UUVP 3568, UUVP 4286, UUVP 10070, and YPM 1905, the paroccipital process constitutes a large and robust element. As observed in the aforementioned Camarasaurus specimens, the paroccipital process has a prominent ventrolateral projection, with the laterally projecting end of the process being strongly flared, with a slight lateral curvature.

Squamosal. Much of the squamosal, particularly the more medial region, is slightly medioposteriorly offset and obscured (Fig. 2). In dorsoposterior view, the squamosal is 
subrectangular, being mediolaterally wider than anteroposteriorly long. The lateral margin is slightly curved and laterally angled. The posterior aspect projects further laterally than the anterior region; unlike the profile morphology of GPDM 220 (Woodruff, Foster, 2017).

Pterygoid and Parasphenoid. Two rarely observed or described Camarasaurus cranial elements are the parasphenoid and the pterygoid. Unfortunately, the overlapping elements restricts much of their view and subsequent description (Fig. 2). We refer readers to Madsen et al. (1995) for proper description of these elements. The visible portion of the pterygoid is subtriangular in lateral view - dorsoventrally taller anteriorly and tapering posteriorly. The posterior $\sim$ half of the pterygoid expresses a large dished depression; similarly reported by Madsen et al. (1995). The visible portion of the parasphenoid is square in lateral view - being as anteroposteriorly elongate a dorsoventrally tall. A single circular opening may be present, and if legitimate, it is either the canal for sphenopalatine artery or the opening for the trigeminal nerve.

Further preparation or more likely CT-scanning could verify and/or elucidate the morphology of these elements.

Sclerotic. In the left anteroventral portion of the orbit is a single, small, rhomboidal piece of bone (Fig. 2). This piece could be a fragment from any of the medial cranial elements, but given its location and superficial resemblance, we suspect that it may represent a segment of the sclerotic ring. While sclerotic rings are not unreported in Camarasaurus (present in USNM V 13786; Madsen et al., 1995), given the nature and visibility of the segment in question, we have left it tentatively identified as sclerotic(?).

Palatine. Underneath the lacrimal is a sub-triangular, flat bone (Fig. 2). While the lacrimal and surround matrix obscure much of the morphology, if this element is in place, it likely represents the palatine. Unfortunately, little if any can be said on its morphology, and for the interim, this element will remain as palatine(?) in Fig. 2.

Dentary. The entirety of the dentary appears to be present (Fig. 2). Unfortunately, the dentary is under the maxilla, so we cannot ascertain much on its morphology - such as, number of teeth present. Though the majority of the dentary morphology cannot be observed, it clearly lacks an anterior prominence at the dentary symphysis (a.k.a. a 'chin'). Woodruff and Foster (2017) noted that this feature is extremely variable in Camarasaurus - prominent in AMNH 467, DMN 957, USNM V 13786, UUVP 3609, and YPM 1905, less so in CM 11338, DINO 28, GMNH-PV 101, GPDM 220, SDSM 114501, and SMA 0002.

Surangular. The surangular is obscured by matrix and the overlying maxilla, jugal and quadratojugal (Fig. 2). In lateral view, the visible portion is rectangular in profile anteroposteriorly longer than dorsoventrally tall. This visible portion likely represent the main body of the element.
The tapered anteromedial process ("handle") and "hatchetshaped" profile (McIntosh et al., 1996a) is not evident, again, likely due to the obstructed view previously mentioned.

Angular. In lateral view, the angular is rectangular - anteroposteriorly longer than dorsoventrall tall (Fig. 2). The dorsal $\sim$ mid length of the element is the dorsoventrally tallest, and the ventral border has a gentle and continuous curvature. The angular anterodorsally articulates with the dentary and surangular, and posteriorly with the articular.

Articular. As Madsen et al. (1995) describe, the articular is a blocky, rectangular element - dorsoventrally taller than anteroposteriorly long (Fig. 2). Unfortunately, matrix obscures what would be the crescent depression that is the articular facet with the quadrate. The articular anteriorly articulates with the angular. While a bit displaced, given that all of the lateral jaw elements are present, we theorize that the medial elements are present as well.

\section{POST-CRANIAL}

Femur. At this time, the right femur is only prepared and visible in posterior view. Even though not prepared in its entirety, the femur of BHI 6200 is still an impressive element and measurements are still possible. Measurements include: greatest proximodistal length: $1372 \mathrm{~mm}$, greatest proximal breadth: $437 \mathrm{~mm}$, least breadth: $255 \mathrm{~mm}$, and greatest distal breadth: $443 \mathrm{~mm}$. Least circumference cannot be measured due to incomplete preparation of the specimen. With a least breadth length of 0.19 , this is a very robust Camarasaurus femur (range is from $0.16-0.20$ ). However, some of the apparent robustness may be due to anteroposterior crushing during diagenesis. In a simplified lineup of Camarasaurus femora (Fig. 3), BHI 6200 is on the larger end of the spectrum. In this lineup, it is important to remember that while ontogimorphs are likely present (i.e., CM 11338), this lineup is not indicative of an ontogenetic series (remember that SMA 0002 and GPDM 220 are histologically mature [Waskow, Sander, 2014; Woodruff, Foster, 2017). In overall profile, the right femur has a slight lateral curvature. The bulbous and spherical head of the femur is offset approximately $25^{\circ}$ to the long axis of the element. In comparison to other Camarasaurus specimens (such as CM 111338, or SMA 0002), the femoral neck in BHI 6200 is lateromedially shorter and stout. The overall femoral morphology of BHI 6200 is more akin to the "robust" (versus "gracile") morph, similar to GMNH-VP 101 (McIntosh et al., 1996a). The fourth trochanter is medially situated and just proximal to the femoral midlength. At the distal end, the medial and lateral condyles are sub-equal in size. The lateral condyle projects more distally of the two condyles. Further preparation of the element will be needed for detailed a discussion of its morphology. 


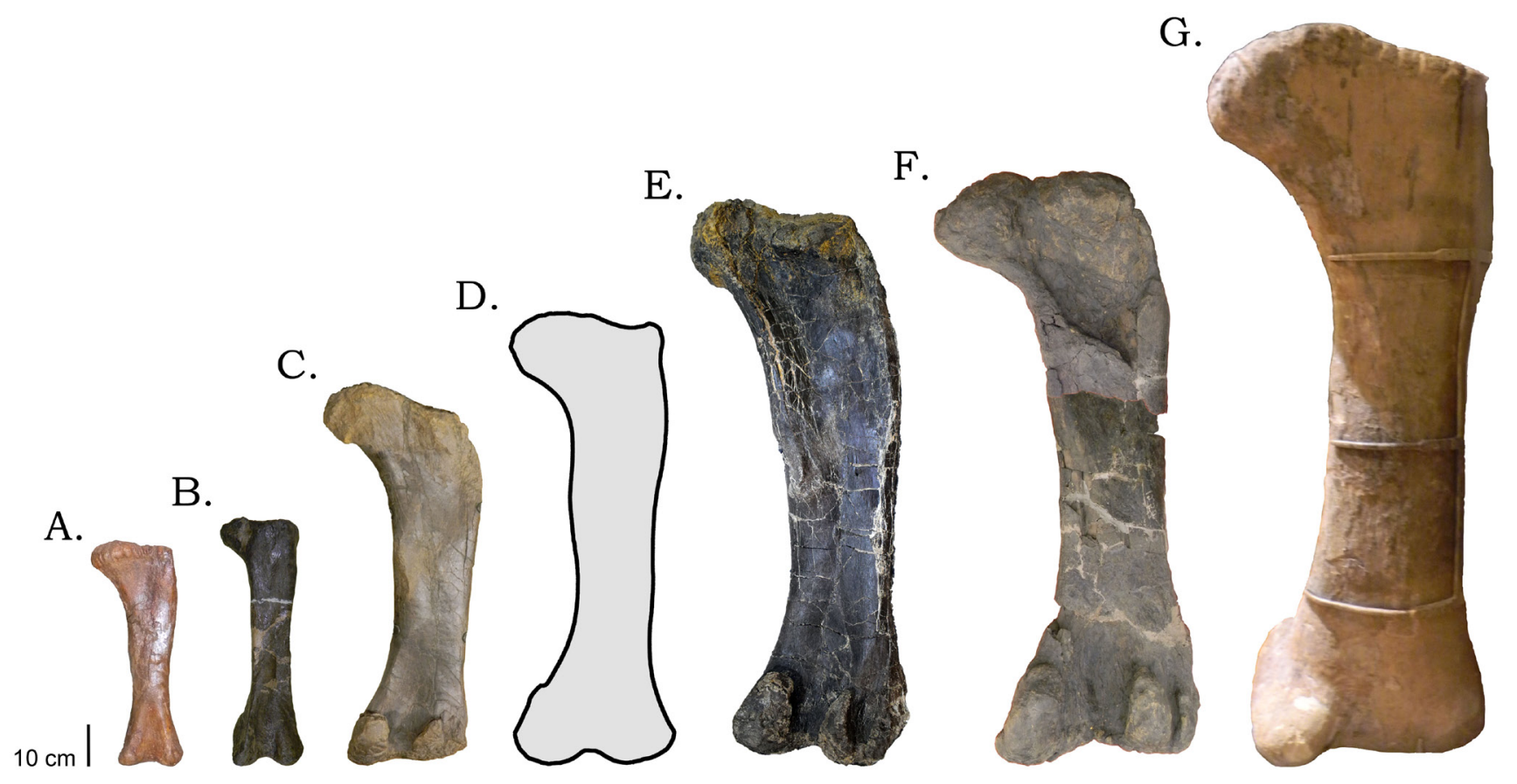

Fig. 3. Femoral lineup of Camarasaurus specimens

A. CM 11338; B. AMNH 911; C. SMA 0002; D. GPDM 220 (note, this element is incomplete so the silhouette represents a reconstructed size); E. BHI 6200; F. CM 36021; G. AMNH 5761. All specimens to scale. Scale bar $=10 \mathrm{~cm}$

\section{D GEOMETRIC MORPHOMETRICS}

Landmark-based geometric morphometric analysis was conducted on ten skulls of Camarasaurus. Five are identified as $C$. lentus (within the previous literature), two as $C$. grandis (within the previous literature), and three as Camarasaurus sp. As will be elaborated on in the Discussion, the GM results discussed herein come from the estimated dataset.

Based on the relative size, varying maturational states are also present within the morphometric dataset as well (i.e., CM 11338 being a very immature specimen of C. lentus). The first four Principal Component (PC) axes describe over $95 \%$ of the variation. PC 1 and PC 2 account for the greatest variability $(73.7 \%$ and $14.9 \%$ respectively), followed by PC 3 and PC 4 (5.01\% and 2.49\% respectively). Unlike other PC analyses that find pronounced distinctness between species (i.e., pachycephalosaurids; Woodruff et al., 2021), there is very little, if any, distinctiveness within the Camarasaurus dataset (Fig. 4). The C. grandis GMNH-PV 101 and Camarasaurus sp. BHI 6200 morphospatially plot as being distinct from $C$. lentus.

\section{DISCUSSION}

\section{CRANIAL VARIATION}

\section{Maturational status of BHI 6200}

Unfortunately, as of this publication, no elements were histologically examined to determine the maturational status or age of BHI 6200. Previously within Dinosauria, relative size would be used as a proxy for maturity (Dodson, 1976; see Carr, 2020 and citations within). Such has been done explicitly within Camarasaurus, but the specimen GPDM 220 exemplarily illustrates that size and age are not undeviating proxies (not just a further example within Dinosauria, but particularly within this genus).

Likewise, degree of skeletal fusion has previously been used to infer maturity (Brochu, 1996; 1999; Irmis, 2007; Ikejiri, 2012). Thus, following this line of reasoning, the largely un-fused cranial elements of BHI 6200 would seem to indicate immaturity. While fusion patterns in mammals largely correspond to maturity, and fusion patterns have been docu- 

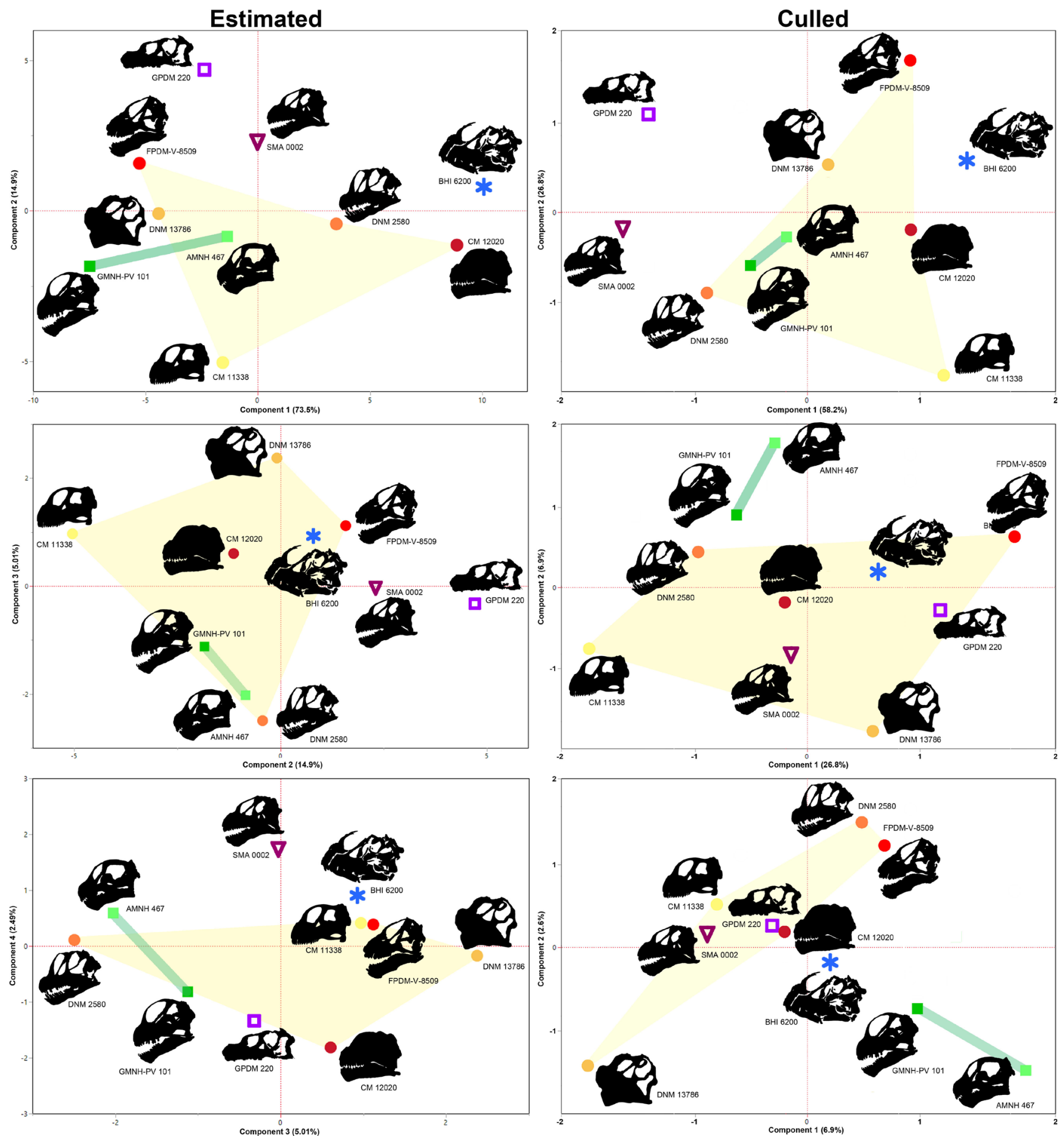

Fig. 4. 2D PCA of PC 1- 4 of the Camarasaurus cranial dataset

Estimated landmark data on the left column, culled landmark data on the right column. Yellow rhomboid corresponds to the hypothetical C. lentus morphospace, and the green line to the hypothetical C. grandis morphospace. Though each specimen is a different color, the same shape corresponds to specimens of the same species. Skull silhouettes and id labels correspond to each specimen. Skulls not to scale 
mented in other archosaurs (Irmis, 2007) such a trend or pattern has not been established in non-avian dinosaurs.

The relative size and morphologies of BHI 6200 could, for the interim, support the idea that this individual was more skeletally mature (this is a testable histologic hypothesis). However, the largely unfused cranial elements (also seen in GMNH-PV 101), strongly indicate that at least within Camarasaurus, the majority of the cranial elements remained un-fused throughout an extended period of life (a trait observed in other dinosaur clades as well [Larson, 2008; Bailleul et al., 2016]).

\section{Taxonomy}

While BHI 6200 possess the cranial autapomorphies of Camarasaurus (Wilson, 2002), the species designation is much more problematic. Currently, there are four valid species of Camarasaurus: C. lentus, C. grandis, C. supremus, and C. lewisi. As Woodruff and Foster (2017) note, of these, C. lentus and C. grandis are the most abundant $(11.1 \%$ and $9.1 \%$ of MNI, respectively), while C. lewisi and C. supre$m u$ are rarer $(1.5 \%$ and $4.5 \%)$. And while these species are recognized on particular 'autapomorphies' or combinations of characters, many of these designations are historic, and there are no uniform or current species diagnoses. While Ikejiri (2005) and Woodruff, Foster (2017) could map Camarasaurus species 'zones', BHI 6200 was from outside of the recognized 'zones' (Fig. 5). Additionally, these species zonations may in fact be tenuous constructs based on apparent stratigraphic distributions and potentially variable identifications. While not truly a "wastebasket" genus, within the Morrison Formation, 'Camarasaurus sp.' seems to be the simple default for any non-Brachiosaurus macronarian.

According to Ikejiri (2005), C. lentus can be differentiated from $C$. grandis on the basis of wider neural arches in the anterior dorsal vertebrae and in having less transversely expanded dorsal ends of the neural spines in the anterior caudal vertebrae (though in many specimens, this distinction is less clear and highly variable; J. Foster pers. comm.); C. grandis has narrow dorsal neural arches and significantly expanded caudal neural spines. Interestingly, C. supremus has the wide neural arches of $C$. lentus, but the expanded caudal neural spines of $C$. grandis. Additionally, McIntosh (1990) differentiated that in $C$. grandis, the neurocentral synostosis is at the level of the apex of the neural canal, versus along the base of the canal in C. lentus."Cathetosaurus" lewisi was erected by Jensen (1988). Jensen (1988) recognized seven characters that were diagnostic of "Cathetosaurus", and they were all postcranial. However, McIntosh et al. (1996b) synonymized "Cathetosaurus" into Camarasaurus. McIntosh et al. (1996b) claimed that four of the "Cathetosaurus" characters were indicative of extreme maturity, yet three of the then newly distinguishing characters - deep and narrow bifurcation in the presacral vertebrae, a forward rotation of the ilium, and a steep angle of the posterior chevron articular facets, are now considered to be ontogenetic as well (Woodruff, Foster, 2017).

Thus, it would appear, for the time being, that there are no recognized species-diagnostic characters of Camarasaurus crania. So, until the post-crania of BHI 6200 are prepared, we can only tentatively identify it as Camarasaurus sp. Said cranial characters likely do exist, but an echoed sentiment among Morrison Formation sauropod workers is that the genus is in desperate need of revision. Being the most abundant dinosaur in the formation, enough specimens of Camarasaurus from different geographical areas, stratigraphic intervals, and ontogenetic states exist that theoretically, all of this should be possible to examine and determine; and that Camarasaurus could represent the ideal taxon for such sauropod analyses.

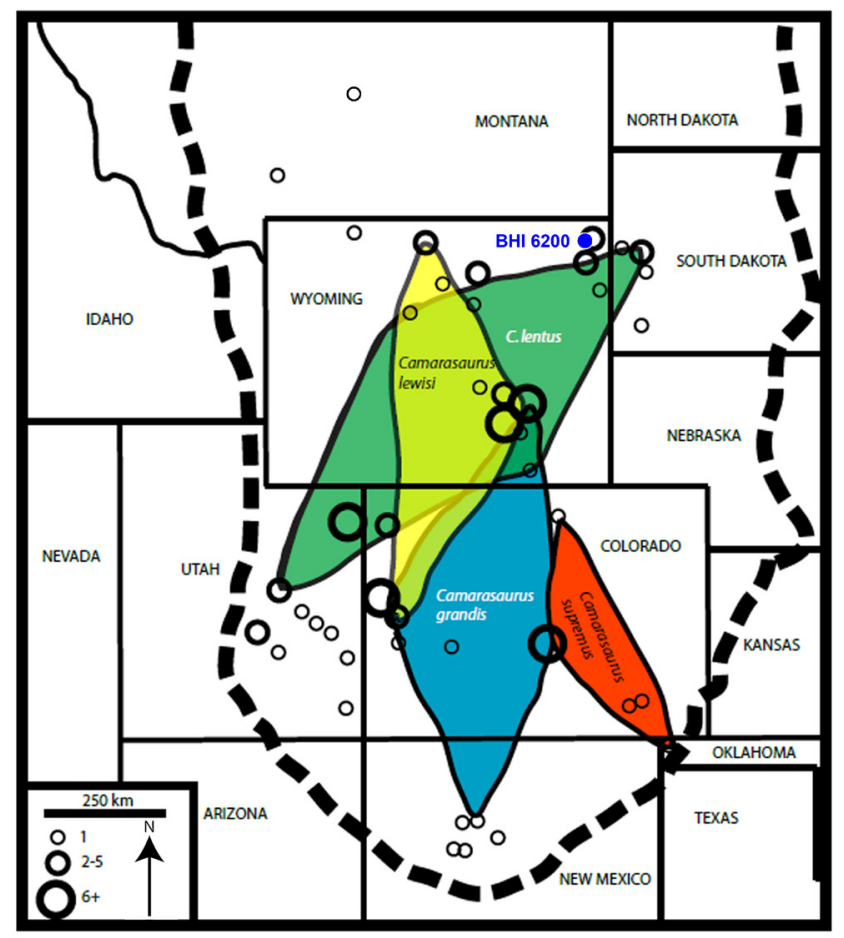

Fig. 5. Distribution of the Camarasaurus species 'zones' within the Morrison Formation with the location of BHI 6200 denoted in blue. Modified from Woodruff, Foster (2017) 


\section{D geometric morphometrics and sources of cranial variation}

Due to the number of missing landmarks from the culled dataset (25 remaining landmarks), for the GM discussion, we have opted to discuss the results from the estimated dataset. There are certainly negatives of estimating landmarks; mainly it could be assigning an inaccurate spatial location, and with more specimens that are spatially similar (which could be a genus or species), the missing landmarks will be more heavily estimated towards the dominating mean. Given that this analysis only examined a single genus, and nearly half of the spatial data would be missing, we opted for the estimated set. However, both estimated and culled landmark PCAs are in Fig. 4.

The PCA results, in regards to BHI 6200 and Camarasaurus taxonomy, are interesting. As mentioned previously herein, unlike other dinosaurian cranial analyses that found tight ontogenetic clustering and clearly distinct taxonomic morphospaces (such as Woodruff et al., 2021), this analysis had large spatial areas within a presumed ontogenetic series, and overlapping taxonomic spaces.

In PC 1, there is a large morphospace represented by $C$. lentus (Fig. 4). The smallest (presumably most immature) specimen - CM 11338 - plots away along the negative axis from the other, larger and presumably more mature $C$. lentus specimens. However, unlike the ontogenetically graded clusters seen in Woodruff et al. (2021), the remaining $C$. lentus specimens appear to be distributed across the morphospace irrespective of maturity. The two $C$. grandis specimens (AMNH 467 and GMNH-PV 101), while not defining a true morphospace (three being the minimum number) do show a potential morphospatial overlap with that of C. lentus (Fig. 4). Interestingly, and if true, the presumably more immature AMNH 467 associates more with comparably mature(?) C. lentus. In PC 2, C. grandis and C. lentus are morphospatially indistinguishable (Fig. 4). BHI 6200 is indistinct from this grouping as well, and only GPDM 220 and FPDM-V-8509 are spatially distinct (potentially due to their taphonomic distortion/reconstruction).

At this time, the taxonomic placement of BHI 6200 within the PCA may be more nebulous. Along PC 1, BHI 6200 appears to be rather distinct from CM 12020 (Fig. 4). This may indicate that either: 1) BHI 6200 is not a specimen of C. lentus, or 2) if BHI 6200 is later identified to be C. lentus, then this species' morphospace is much more irregular than previously perceived. If BHI 6200 is later determined to not be $C$. lentus, then what species might it be? The wide spatial separation between BHI 6200 and the C. grandis specimens - potentially indicating they are not the same either - only leaves us with two species options: $C$. lewisi or $C$. supremeus. Skulls of these two species are required in the analysis before anymore can be said on this possibility.
Interestingly, the eigenvectors reveal a noteworthy pattern regarding the degrees of variation observed in the $2 \mathrm{D}$ lateral analysis (Table 1). While many of the landmarks have relatively high vector values, there are two 'zones' of the greatest variation. The first are the landmarks associated with the nasal, and the second are the landmarks associated with the postorbital. This is interesting because of the 'external' and 'internal' expression of these elements. Of course, in life there were various forms of connective tissues over these elements - however, even with overlying tissues, the nasal undoubtedly contributed to the 'face' and visual appearance of each specimen; while the postorbital was covered by more cranial musculature, and therefore likely not to have been externally observable in life. One might predict that the morphology of the postorbital to likely represent interspecific variation, while that of the nasal to represent intraspecific variation; or alternatively indicative of more taphonomically distortable region of the skull. More analysis of these elements, and a greater sample set is likely required to further examine and answer these questions.

\section{Cranial allometry in Camarasaurus?}

The skull of BHI 6200 is the second largest Camarasaurus skull reported to-date (Table 2). That in and of itself is an impressive statistic. However, its 'average' femur length indicates that it was not the second largest, nor as physically imposing of a specimen as the skull would seem to indicate. The prolific number of Camarasaurus specimens provides several represented by complete skulls and limb elements. As seen in the natural world today, individual variation is prolific and found across the entire skeleton. While dinosaurian individual variation is often noticeably evident in cranial displays (i.e., ceratopsian horns; Farlow, Dodson, 1975), variation existed throughout the post-crania as well. The Camarasaurus SMA 0002 serves as a very good example. While much of the skeleton seems to proportion, the limb elements are markedly not so. The proportionally shorter zeugopodial elements (ulnae, radii, tibiae, and fibulae), produce very short limbs - a 'dachshund reminiscent' sauropod. (for comparison, GMNH-PV 101 femur:tibia 1.59, CM 11388 femur:tibia 1.58 humerus:ulna 1.5 , USNM 13786 femur:tibia 1.56 humerus:ulna 1.43, compared to SMA 0002 femur:tibia 1.76 humerus:ulna 1.19).

However, so many specimens represented by cranial and postcranial material highlights an odd occurrence within this genus. Superficially, many specimens of Camarasaurus appear to have a proportionally large head for their body size. Proportionally large head:body ratios are a hallmark of altriciality; therefore, a large head:body ratio throughout maturity might constitute neotenic retention. The smallest 
PCA eigenvalues based on the 2D landmarks (from the estimated landmark dataset)

\begin{tabular}{|c|c|c|c|c|}
\hline & PC 1 & PC 2 & PC 3 & PC 4 \\
\hline Landmark 1 & 0.10792 & 0.27210 & 0.07815 & 0.12511 \\
\hline Landmark 2 & 0.13791 & -0.13842 & 0.29406 & 0.04193 \\
\hline Landmark 3 & 0.13469 & 0.22940 & 0.03905 & 0.00660 \\
\hline Landmark 4 & 0.15474 & -0.12803 & 0.13988 & -0.00709 \\
\hline Landmark 5 & 0.12689 & 0.23546 & -0.02885 & 0.21543 \\
\hline Landmark 6 & 0.15878 & -0.12977 & -0.03314 & 0.03809 \\
\hline Landmark 7 & 0.12475 & 0.22252 & -0.07465 & 0.20349 \\
\hline Landmark 8 & 0.14064 & -0.15294 & 0.23983 & -0.02206 \\
\hline Landmark 9 & 0.12851 & 0.10298 & 0.23372 & 0.22993 \\
\hline Landmark 10 & 0.14064 & -0.12748 & 0.29434 & -0.03019 \\
\hline Landmark 11 & 0.07927 & -0.00706 & 0.07659 & 0.77863 \\
\hline Landmark 12 & 0.12156 & -0.14188 & 0.37611 & 0.00481 \\
\hline Landmark 13 & 0.13273 & 0.19826 & 0.08609 & -0.17449 \\
\hline Landmark 14 & 0.15323 & -0.13908 & 0.16161 & -0.05110 \\
\hline Landmark 15 & 0.15191 & 0.15071 & 0.12172 & 0.02945 \\
\hline Landmark 16 & 0.15705 & -0.13863 & -0.04692 & 0.09016 \\
\hline Landmark 17 & 0.15415 & 0.15119 & 0.08352 & -0.03762 \\
\hline Landmark 18 & 0.15996 & -0.12632 & -0.01113 & 0.02797 \\
\hline Landmark 19 & 0.13713 & 0.18712 & 0.05611 & -0.22372 \\
\hline Landmark 20 & 0.15502 & -0.13922 & 0.12432 & -0.08355 \\
\hline Landmark 21 & 0.13751 & 0.18512 & 0.07973 & -0.16515 \\
\hline Landmark 22 & 0.15525 & -0.14061 & 0.10240 & -0.09931 \\
\hline Landmark 23 & 0.14821 & 0.16682 & -0.02274 & -0.12795 \\
\hline Landmark 24 & 0.14916 & -0.17326 & 0.05488 & -0.04889 \\
\hline Landmark 25 & 0.15609 & 0.11491 & 0.10287 & -0.03361 \\
\hline Landmark 26 & 0.15484 & -0.14300 & -0.05209 & 0.01495 \\
\hline Landmark 27 & 0.15726 & 0.12850 & 0.01957 & -0.12344 \\
\hline Landmark 28 & 0.15514 & -0.13370 & -0.03956 & -0.12185 \\
\hline Landmark 29 & 0.15860 & 0.13137 & 0.01921 & -0.03213 \\
\hline Landmark 30 & 0.16014 & -0.11575 & 0.05371 & -0.01327 \\
\hline Landmark 31 & 0.15955 & 0.09047 & -0.10008 & -0.01338 \\
\hline Landmark 32 & 0.14834 & -0.12778 & -0.24099 & 0.03122 \\
\hline Landmark 33 & 0.15966 & 0.10305 & -0.05316 & 0.02884 \\
\hline Landmark 34 & 0.15252 & -0.13008 & -0.20178 & 0.00959 \\
\hline Landmark 35 & 0.15762 & 0.10846 & -0.06329 & 0.08913 \\
\hline Landmark 36 & 0.15317 & -0.13666 & -0.16027 & -0.03815 \\
\hline Landmark 37 & 0.16105 & 0.08853 & -0.05760 & 0.01130 \\
\hline Landmark 38 & 0.14882 & -0.13430 & -0.23038 & 0.01121 \\
\hline Landmark 39 & 0.16122 & 0.08554 & -0.16134 & -0.00036 \\
\hline Landmark 40 & 0.13488 & -0.17330 & -0.21518 & 0.09818 \\
\hline Landmark 41 & 0.15851 & 0.10121 & -0.14082 & -0.00310 \\
\hline Landmark 42 & 0.14331 & -0.11635 & -0.28882 & 0.04828 \\
\hline Landmark 43 & 0.15498 & 0.12676 & -0.11693 & -0.06100 \\
\hline Landmark 44 & 0.15592 & -0.13664 & -0.11955 & -0.00829 \\
\hline Landmark 45 & 0.14827 & 0.14426 & -0.12297 & -0.12223 \\
\hline Landmark 46 & 0.15583 & -0.12701 & -0.03482 & -0.02045 \\
\hline
\end{tabular}

Table 1

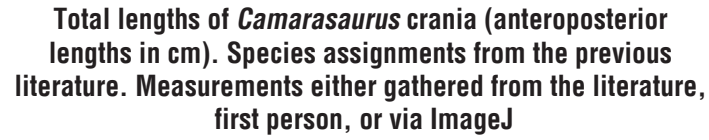

Total lengths of Camarasaurus crania (anteroposterior lengths in $\mathrm{cm}$ ). Species assignments from the previous literature. Measurements either gathered from the literature, first person, or via ImageJ

\begin{tabular}{|l|c|c|}
\hline \multicolumn{1}{|c|}{ Specimen } & Species & Skull length \\
\hline CM 11338 & C. lentus & $26.90 \mathrm{~cm}$ \\
\hline DINO 2580 & C. lentus & $48.20 \mathrm{~cm}$ \\
\hline YPM 1905 & C. grandis & $48.33 \mathrm{~cm}$ \\
\hline USNM V 13786 & C. lentus & $49.94 \mathrm{~cm}$ \\
\hline DINO 28 & C. lentus & $50.53 \mathrm{~cm}$ \\
\hline AMNH 467 & C. grandis & $52.93 \mathrm{~cm}$ \\
\hline SMA 0002 & sp. & $54.90 \mathrm{~cm}$ \\
\hline GPDM 220 & sp. & $65.70 \mathrm{~cm}$ \\
\hline DINO 975 & C. lentus & $66.55 \mathrm{~cm}$ \\
\hline GMNH-PV 101 & C. grandis & $68.58 \mathrm{~cm}$ \\
\hline CM 12020 & C. lentus & $70.50 \mathrm{~cm}$ \\
\hline BHI 6200 & sp. & $78.46 \mathrm{~cm}$ \\
\hline FPDM-V-8509 & C. lentus & $83.59 \mathrm{~cm}($ reconstructed) \\
\hline
\end{tabular}

Camarasaurus with known cranial and limb material is the immature(?) C. lentus CM 11338. While being the smallest skeleton (and one of the most complete sauropods ever discovered), CM 11338 still constitutes a large terrestrial vertebrate - a body mass of approximately $1,184 \mathrm{~kg}$ (minimum femur circumference $292 \mathrm{~mm}$; using the Mazetta et al. [2004] formula: $\log$ body mass $=2.955 \cdot \log$ femur circumference - 4.166). While smaller Camarasaurus cranial material is known (Britt, Naylor, 1994; Woodruff, Foster, 2017), corresponding limb material is not. At this time, we cannot predict the head to body ratio of embryonic or hatchling Camarasaurus; but by comparing skull length to femur length, we see that CM 11338 has a skull approximately $46 \%$ the length of the femur. Interestingly, in larger (presumably increasingly more mature) specimens - YPM 1905, GMNH-PV 101, and CM 12020 - the skull:femur ratio has a similar percentage ( 46\%: GMNH-PV 101 and YPM 1905; $\sim 49 \%$ CM 12020). These ratios are consistent with what we will refer to as 'normal' proportions (Fig. 6).

Conversely, several specimens - BHI 6200, USNM V 13786, GPDM 220, and SMA 0002 - have higher skull:femur proportions; approximately $57 \%$ in BHI 6200 and $58 \%$ in GPDM 220, SMA 0002, and USNM V 13786 (Fig. 6); and of taxonomic interest, these 'bobblehead' specimens appear to 'violate' a synapomorphy of Sauropodomorpha (skull length less than $50 \%$ of the femur length; sensu Wilson, Sereno, 1998). If neotenic cranial proportions were present in these unusual specimens, we would expect values similar to that of CM 11338. However, this is not the case. In these 'bobblehead' specimens, the ratio is higher, suggesting that the rate of skull size increases through growth with respect 


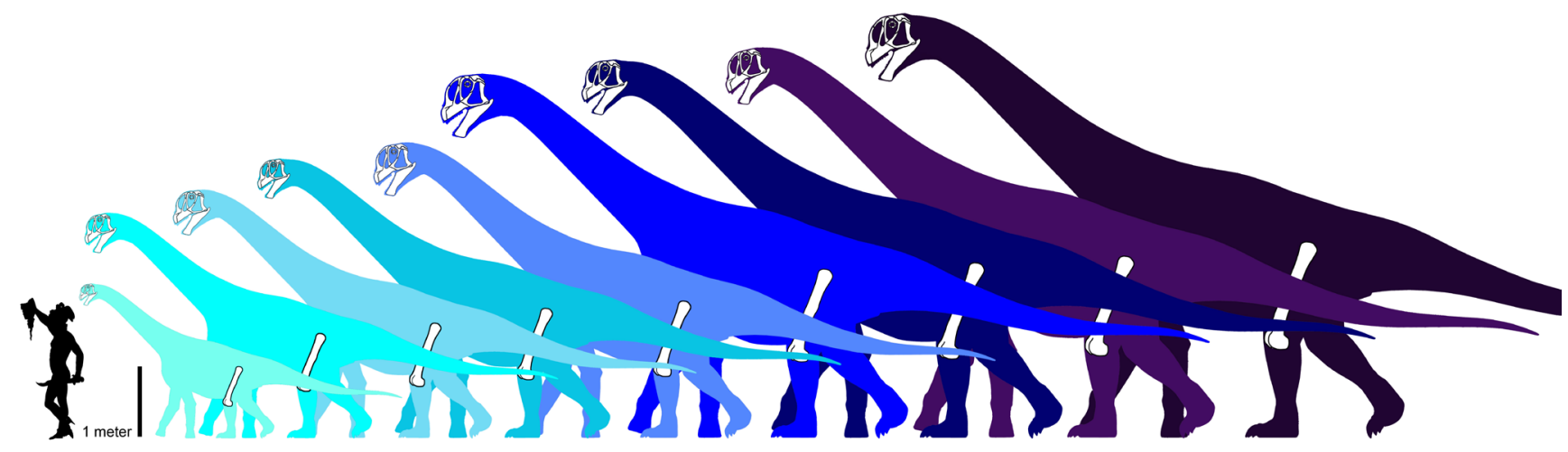

Fig. 6. Camarasaurus specimens highlighting the two cranial proportion 'morphs'

From left to right: CM 11338, DMN 13786, SMA 0002, YPM 1905, GPDM 220, BHI 6200, CM 12020, GMNH-PV 101, FPDM-V-8509. All specimens to scale. Scale bar $=1$ meter. Human scale bar is Benvenuto Cellini's Perseus with the Head of Medusa, depicting Perseus as 1.86 meters tall. Camarasaurus skeletal reconstruction by S. Hartman

to femur length. In comparing both skull:femur length (Fig. 7), and LOG skull length:PC 1 scores (Fig. 8), we see two distinct associations (although not as dramatic a distinction in LOG skull:PC scores compared to skull:femur length). Additionally, in both analyses, there is an allometric coefficient greater than 1 , indicating positive allometry in these specimens. Interestingly, in the 'normal' specimens, there is no early ontogenetic cranial proportion overlap. In these specimens, throughout maturity, the cranial proportions remain more isometric.

A worthwhile consideration is the effects of taphonomic distortion. All of these skulls exhibit various forms of distortion, and theoretically, such could cause secondary elongation. In consideration of such, we additionally examined other element ratios. Could potential distortion be evident amongst other cranial proportions? In comparing the LOG skull length

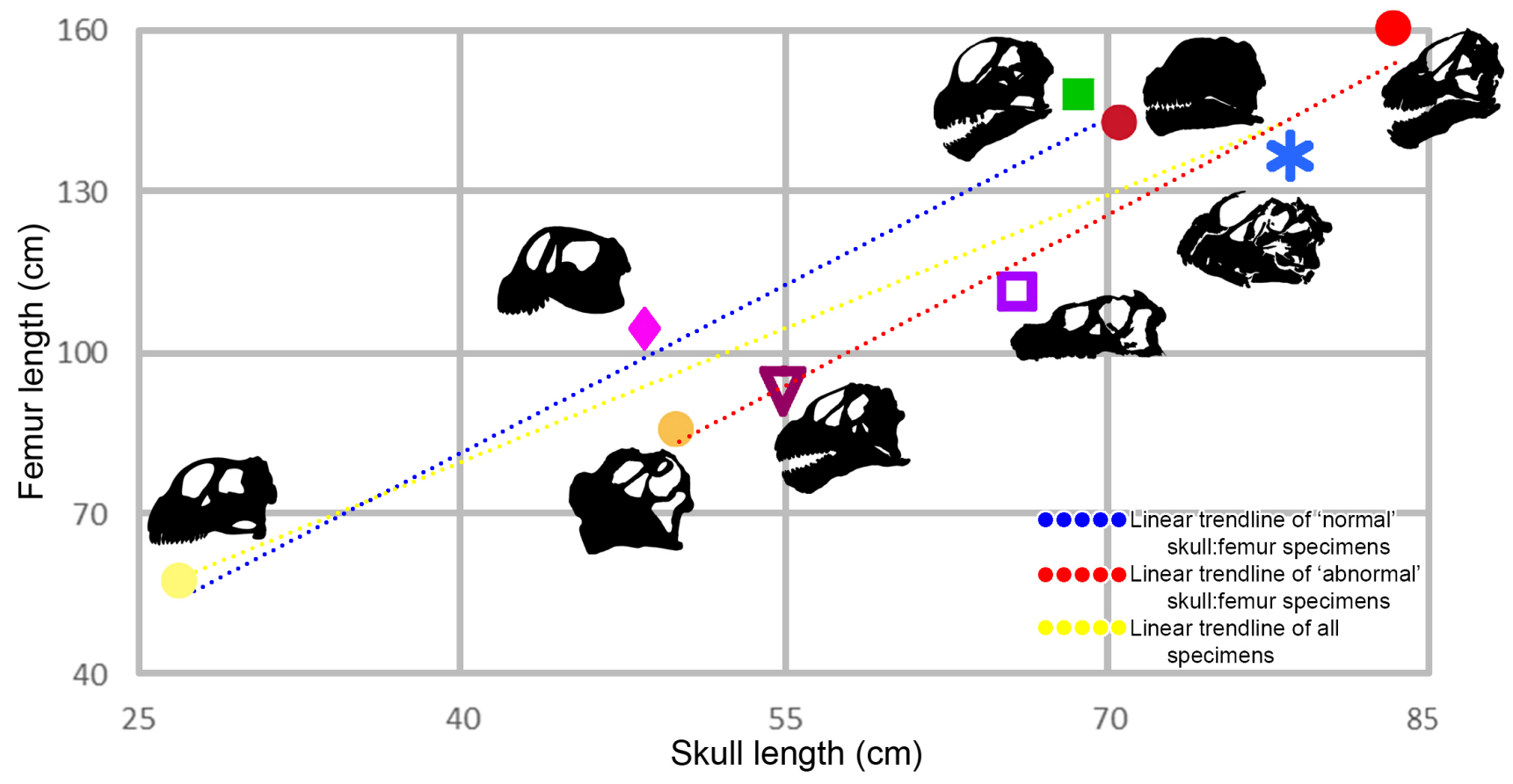

Fig. 7. Skull length versus femur length in Camarasaurus indicating the two cranial 'morphs'

Identification of cranial silhouettes in Fig. 4. Though each specimen is a different color, the same shape corresponds to specimens of the same species. Skull silhouettes and id labels correspond to each specimen. Skulls not to scale 

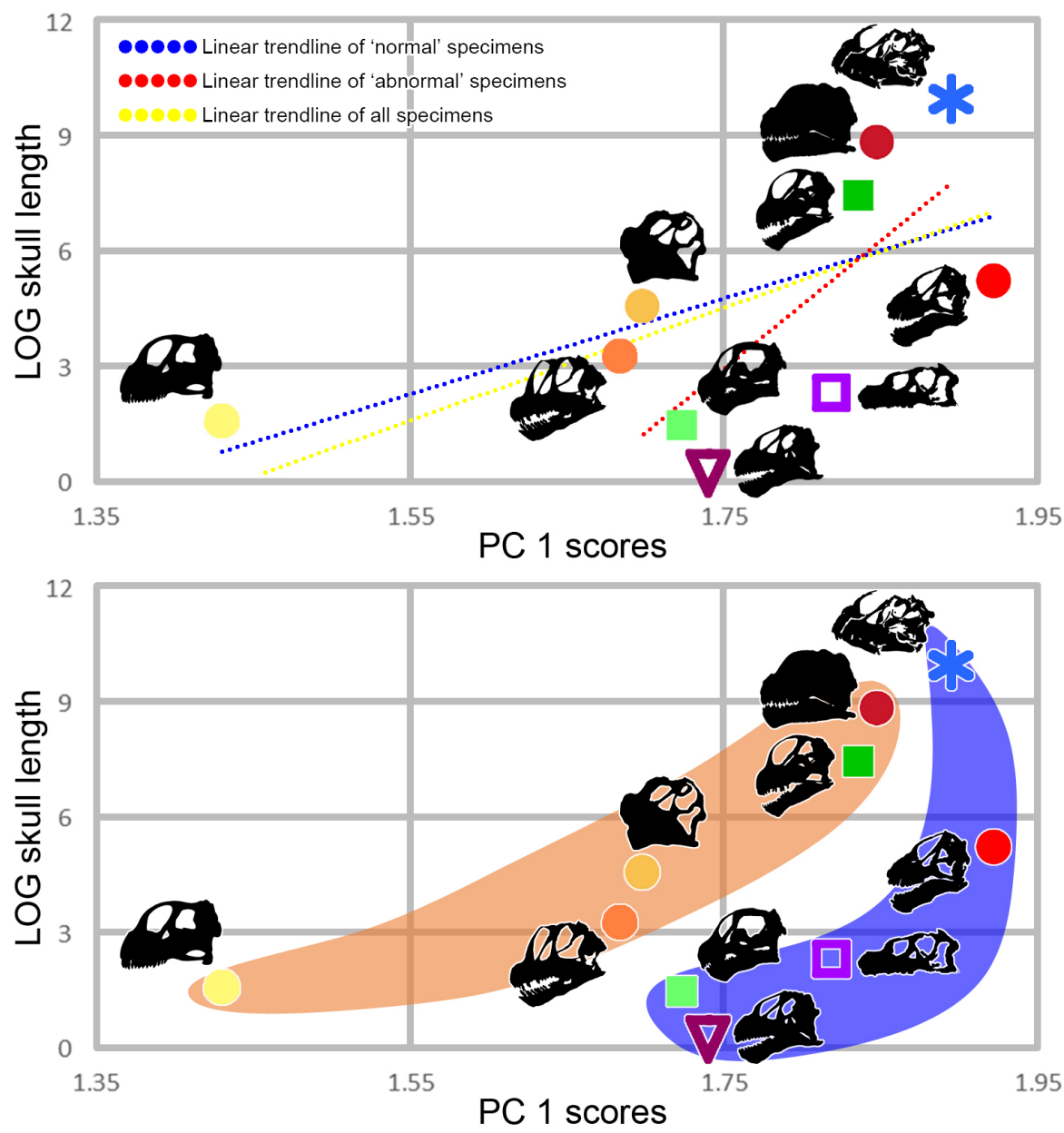

Fig. 8. PC1 scores versus LOG skull length in Camarasaurus.

The top graph shows the specimens with correspond trend lines, while the bottom graph illustrates the two morphs - 'normal' in orange, and 'bobblehead' in blue. Though each specimen is a different color, the same shape corresponds to specimens of the same species. Skull silhouettes and id labels correspond to each specimen. Skulls not to scale

to the LOG length of the premaxillary and maxillary tooth row, no differences exist at all; indicating that within each specimen, cranial variables remain proportional. Interestingly, when comparing tooth row to femur length, while two groupings can be weakly distinguished, these differences are much more subtle and could be argued as indistinguishable. However, in comparison to other postcranial elements, the difference in morphs can be observed. Unfortunately, cranial, vertebral, and femoral data from single specimens is largely lacking, but in two - GPDM 220 (a 'bobblehead' morph) and GMNH-PV101 (a 'normal' morph) - all of this data exists. In comparing the two, the skulls differ in anteroposterior length by less than $3 \mathrm{~cm}$, while the greatest cervical length difference is less than $5 \mathrm{~cm}$. LOG values of the present cervical vertebrae reveals a nearly identical series profile. In comparing the femoral and cervical data, while similar trends are observed, the two specimens are clearly distinguishable and separable (Fig. 9). This is noteworthy because in their investigation of GPDM 220, Woodruff and Foster (2017) noted that proportionally, the skull seemed larger than it should in relation to the cervical series.

So, what best explains the two groups of cranial size? Initially, one could propose that such distinct groupings denote alternative taxonomic distinctions, so perhaps, contra traditional systematics, we are in fact looking at only two distinct species. However, the cranial:femur dataset herein is comprised of several historically recognized species of Camarasaurus. The same species, such as C. lentus, is observed in both the 'normal' and 'bobblehead' skull sized groups. If the species designations used in this analysis are correct, then this indicates that the different proportioned skulls are not indicative of differing species. 

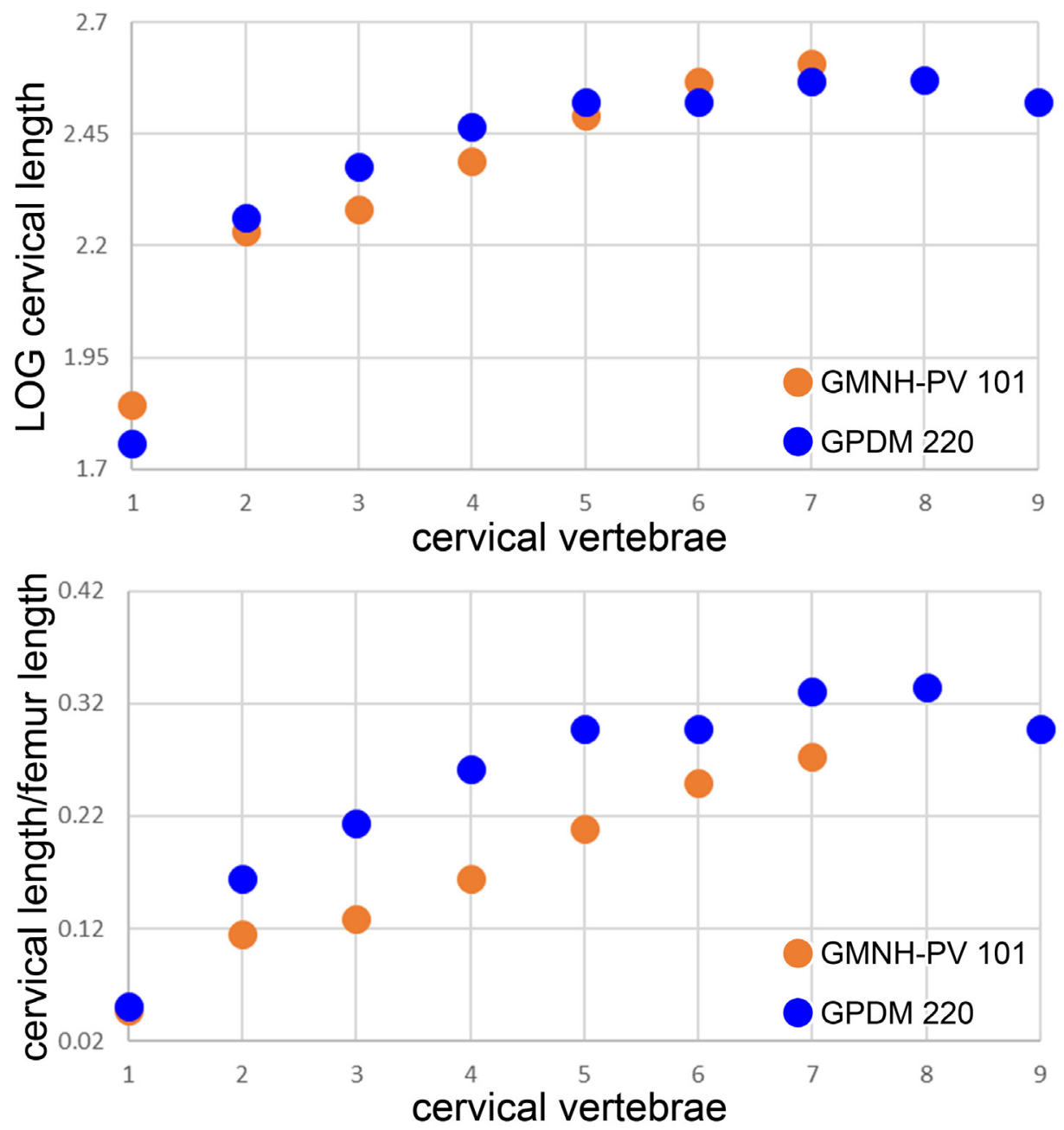

Fig. 9. Serial position of cervical vertebrae compared to LOG cervical length (A) and cervical length/femur length (B) in GMNH-PV 101 (orange circle) and GPDM 220 (blue circle)

At this time our only possible explanation for the increased cranial size in some Camarasaurus is that it is a further, and albeit more extreme, example of individual variation. While we cannot at this time rule out additional causal agents - such as possible sexual dimorphism - we greatly welcome future studies that seek to further examine and explain these unusual cranial proportions.

\section{CONCLUSIONS}

Known from a seemingly complete and articulated skull, BHI 6200 further allows us to better understand the morphology and variability within the macronarian genus Camarasaurus. While BHI 6200 is the second largest Camarasaurus skull to-date, postcrania reveals that body wise, it is not the second largest specimen. This may seem contradictory, but BHI 6200 - along with the subsequent recognition of cranium-body size variability in several other specimens indicates cranial allometry within the genus. This allometry consists of 'normal' specimens with crania $<50 \%$ the length of the femur, and those with crania nearly $60 \%$ the length of the femur. As yet, the mechanism behind these differing cranial morphs is unknown. As cranial morphology is highly variable among specimens of Camarasaurus, and cranialbody size patterns are not distinct among species, it is likely not taxonomically informative, or at least not as historically defined. Dimorphism or intra-/interspecific variation are other possible mechanisms, and future analyses should consider such possibilities. While the mechanism of this cranial allometry is as yet unknown, it does emphasize that there is still much to study and learn from such abundant fossil taxa. 
Acknowledgements. Thanks to L. and E. Waugh for the opportunity to collect, learn from, and share this specimen with the scientific community. J. Foster provided invaluable discussion and review on all things Camarasaurus related. O. Demuth, R. Hunt-Foster, T. Imai, A. Maltese, and T. Sekiya provided other Camarasaurus specimens used in the geometric morphometric analysis. M. Lamanna, A. Henrici, J. Sawchak, and H. Bateman provided measurements of CM 12020. T. Imai, T. Sekiya, and B. Simon provided photographs and measurements of FPDM-V-8509. R. Hunt-Foster provided measurement data for CM 11338. D. Evans provided valuable discussion on assessing allometry. Thanks to S. Hartman for the use of his Camarasaurus skeletal used in Fig. 6. Finally, thanks to V. Díez Díaz and J. Foster for comments and reviews that greatly improved the previous version of this manuscript.

\section{REFERENCES}

ADAMS D.C., OTÁROLA-CASTILLO E., 2013 - Geomorph: an R package for the collection and analysis of geometric morphometric shape data. Methods in Ecology and Evolution, 4: 393-399.

ARBOUR V.M., CURRIE P.J., 2012 - Analyzing taphonomic deformation of ankylosaur skulls using retrodeformation and finite element analysis. PloS one, 7: e39323.

BAILLEUL A.M., SCANNELLA J.B., HORNER J.R., EVANS D.C., 2016 - Fusion patterns in the skulls of modern archosaurs reveal that sutures are ambiguous maturity indicators for the Dinosauria. PLOS ONE, 11, 2: e0147687. doi:10.1371/journal. pone. 0147687.

BENAZZI S., GRUPPIONI G., STRAIT D.S., HUBLIN J.J. 2014 Virtual reconstruction of KNM-ER 1813 Homo habilis cranium. American Journal of Physical Anthropology, 153: 154-160.

BROCHU C.A., 1996 - Closure of neurocentral sutures during crocodilian ontogeny: implications for maturity assessment in fossil archosaurs. Journal of Vertebrate Paleontology, 16: 49-62.

BROCHU C.A., 1999 - Phylogeny, systematics, and historical biogeography of Alligatoroidea. Society of Vertebrate Paleontology Memoir, 6: 9-100.

BRITT B.B., NAYLOR B.G. 1994 - An embryonic Camarasaurus (Dinosauria, Sauropoda) from the Upper Jurassic Morrison Formation (Dry Mesa Quarry, Colorado). In: Dinosaur Eggs and Babies (eds. K. Carpenter et al.): 256-264. Cambridge, UK, Cambridge University Press.

BUSER T. J., SIDLAUSKAS B.L., SUMMERS A.P., 2018 -2D or not $2 \mathrm{D}$ ? Testing the utility of $2 \mathrm{D}$ vs. $3 \mathrm{D}$ landmark data in geometric morphometrics of the sculpin subfamily Oligocottinae (Pisces; Cottoidea). The Anatomical Record, 301: 806-818.

CARR T., 2020 - A high -resolution growth series of Tyrannosaurus rex obtained from multiple lines of evidence. PeerJ, 8: e9192 https://doi.org/10.7717/peerj.9192.

COONEY C.R., BRIGHT J.A., CAPP E.J., CHIRA A.M., HUGHES E.C., MOODY C.J., NOURI L.O., VARLEY Z.K.,
THOMAS G.H., 2017 - Mega-evolutionary dynamics of the adaptive radiation of birds. Nature, 542: 344-347.

CUFF A.R., RAYFIELD E.J., 2015 - Retrodeformation and muscular reconstruction of ornithomimosaurian dinosaur crania. PeerJ, 3: e1093.

DODSON P., 1976 - Quantitative aspects of relative growth and sexual dimorphism in Protoceratops, Journal of Paleontology, 50, 5: 929-940.

FALKINGHAM P.L., 2012 - Acquisition of high resolution threedimensional models using free, open-source, photogrammetric software. Palaeontologia Electronica, 15.

FARLOW J., DODSON P., 1975 - The behavioral significance of frill and horn morphology in ceratopsian dinosaurs. Evolution, 29: $353-361$.

FOSTER, J.R., 2001 - Relative abundances of the Sauropoda (Dinosauria, Saurischia) of the Morrison Formation and implications for Late Jurassic paleoecology of North America. Mesa Southwest Museum Bulletin, 8: 47-60.

GUNZ P., MITTEROECKER P., 2013 - Semilandmarks: a method for quantifying curves and surfaces. Hystrix, the Italian Journal of Mammalogy, 24: 103-109.

HEDRICK B.P., DODSON P., 2013 - Lujiatun psittacosaurids: understanding individual and taphonomic variation using 3D geometric morphometrics. PLoS One, 8: e69265.

IKEJIRI T., 2005 - Distribution and biochronology of Camarasaurus (Dinosauria, Sauropoda) from the Jurassic Morrison Formation of the Rocky Mountain region. New Mexico Geological Society, 56th Field Conference Guidebook, 56: 367-379.

IKEJIRI T., 2012 - Histology based morphology of the neurocentral synchondrosis in Alligator mississippiensis (Archosauria, Crocodylia). The Anatomical Record: Advances in Integrative Anatomy and Evolutionary Biology, 295, 1: 18-31.

IRMIS R.B., 2007 - Axial skeleton ontogeny in the Parasuchia (Archosauria: Pseudosuchia) and its implications for ontogenetic determination in archosaurs. Journal of Vertebrate Paleontology, 27: 350-361.

JENSEN J.A., 1988 - A fourth new sauropod dinosaur from the Upper Jurassic of the Colorado Plateau and sauropod bipedalism. The Great Basin Naturalist, 48, 2: 121-145.

LARSON P.L., 2008 - Atlas of the skull bones of Tyrannosaurus rex. In: Tyrannosaurus rex, the Tyrant King: 233-243. Bloomington, Indiana: Indiana University Press.

LEFEBVRE R., ALLAIN R., HOUSSAYE A., CORNETTE R., 2020 - Disentangling biological variability and taphonomy: shape analysis of the limb long bones of the sauropodomorph dinosaur Plateosaurus. PeerJ, 8: e9359.

MADSEN J.H., McINTOSH J.S., BERMAN D.S., 1995 - Skull and atlas-axis complex of the Upper Jurassic sauropod Camarasaurus Cope (Reptilia: Saurischia). Bulletin of Carnegie Museum of Natural History, 31: 1-115.

MAIDMENT S.C.R., MUXWORTHY A., 2019 - A chronostratigraphic framework for the Upper Jurassic Morrison Formation, Western U.S.A. Journal of Sedimentary Research, 89: 1017-1038. MAIDMENT S.C.R., WOODRUFF D.C, HORNER J.R., 2018 A new specimen of the ornithischian dinosaur Hesperosaurus mjosi from the Upper Jurassic Morrison Formation of Mon- 
tana, U.S.A., and implications for growth and size in Morrison stegosaurs. Journal of Vertebrate Paleontology, 38: e1406366.

MALLISON H., WINGS O., 2014 - Photogrammetry in paleontology - a practical guide. Journal of Paleontological Techniques, 12, 12: 1-31.

MAZZETTA G.V., CHRISTIANSEN P., FARIÑA R.A., 2004 Giants and bizarres: body size of some southern South American Cretaceous dinosaurs. Historical Biology, 16, 2/4: 71-83.

McINTOSH J.S., 1990 - Sauropoda. In: The Dinosauria (eds. D.B. Weishampel et al.): pp. 345-401. Berkeley, CA: University of California Press.

McINTOSH J.S., MILLER W.E., STADTMAN K.L., GILLETTE D.D., 1996a - The osteology of Camarasaurus lewisi (Jensen, 1988). Brigham Young University Geology Studies, 41: 73-95.

McINTOSH J.S., MILES C.A., CLOWARD K.C., PARKER J.R., 1996 b - A new nearly complete skeleton of Camarasaurus. Bulletin of Gunma Museum of Natural History, 1: 1-87.

MÜLLER R.T., GARCIA M.S., DA-ROSA Á.A.S., DIAS-DASILVA S., 2018 - Under pressure: Effect of sedimentary compression on the iliac morphology of early sauropodomorphs. Journal of South American Earth Sciences, 88:345-351.

SCHLAGER S., PROFICO A., DI VINCENZO F., MANZI G., 2018 - Retrodeformation of fossil specimens based on 3D bilateral semi-landmarks: Implementation in the $\mathrm{R}$ package "Morpho". PloS one, 13: e0194073.

SERENO P.C., WILSON J.A., 2005 - Structure and evolution of a sauropod tooth battery. In: The sauropods: evolution and paleobiology: 157-177. Berkeley, CA: University of California Press.

TALLMAN M., AMENTA N., DELSON E., FROST S.R., GHOSH D., KLUKKERT Z.S., MORROW A., SAWYER G.J., 2014 Evaluation of a new method of fossil retrodeformation by algorithmic symmetrization: crania of papionins (Primates, Cercopithecidae) as a test case. PloS one, 9(7), e100833.
TAYLOR M.P., WEDEL M.J., NAISH, D. 2009 - Head and neck posture in sauropod dinosaurs inferred from extant animals. Acta Palaeontologica Polonica, 54: 213-220. DOI:https://doi. org/ 10.4202/app.2009.0007.

TSCHOPP E.D., RUSSO J., DZEMSKI G., 2013 - Retrodeformation as a test for the validity of phylogenetic characters: an example from diplodocid sauropod vertebrae. Palaeontologia Electronica, 16: 1-23.

WASKOW K., SANDER P.M., 2014 - Growth record and histological variation in the dorsal ribs of Camarasaurus sp. (Sauropoda). Journal of Vertebrate Paleontology, 34: 852-869.

WILSON J. A., 2002 - Sauropod dinosaur phylogeny: critique and cladistic analysis. Zoological Journal of the Linnean Society, 136: $215-275$.

WILSON J.A., SERENO P.C., 1998 - Early evolution and higherlevel phylogeny of sauropod dinosaurs. Journal of Vertebrate Paleontology, 18(S2), 1-79.

WOODRUFF D.C., FOSTER J.R., 2017 - The first specimen of Camarasaurus (Dinosauria: Sauropoda) from Montana: The northernmost occurrence of the genus. PLOS ONE 12:e177423.

WOODRUFF D.C., TREXLER D., MAIDMENT S.C., 2019 Two new stegosaur specimens from the Upper Jurassic Morrison Formation of Montana, U.S.A. Acta Palaeontologica Polonica, 64, 3: 461-480.

WOODRUFF D.C., CARR T.D., STORRS G.W., WASKOW K., SCANNELLA J.B., NORDÉN K.K., WILSON J.P., 2018 The Smallest Diplodocid Skull Reveals Cranial Ontogeny and Growth-Related Dietary Changes in the Largest Dinosaurs. Scientific Reports, 8: 14341.

WOODRUFF D.C., GOODWIN M.B., LYSON T.R., EVANS D.C., 2021 - Ontogeny and variation of the pachycephalosaurine dinosaur Sphaerotholus buchholtzae, and its systematics within the genus. Zoological Journal of the Linnean Society. https://doi. org/10.1093/zoolinnean/zlaa179. 
Appendix

\section{SUPPLEMENTAL INFORMATION}

Figures 1-3: Elemental measurements of the Camarasaurus sp. BHI 6200. All skulls to scale. Measurements in $\mathrm{cm}$.

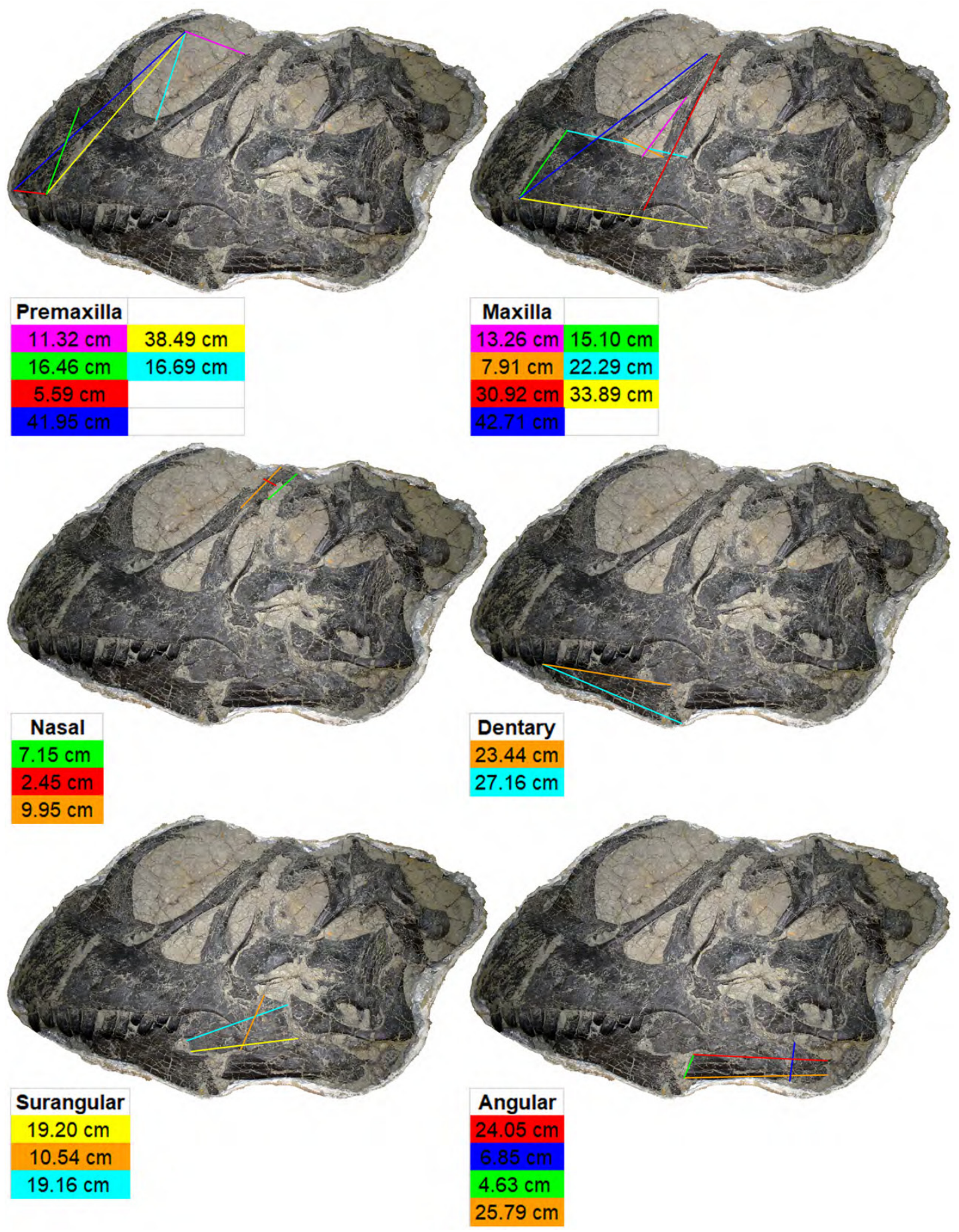



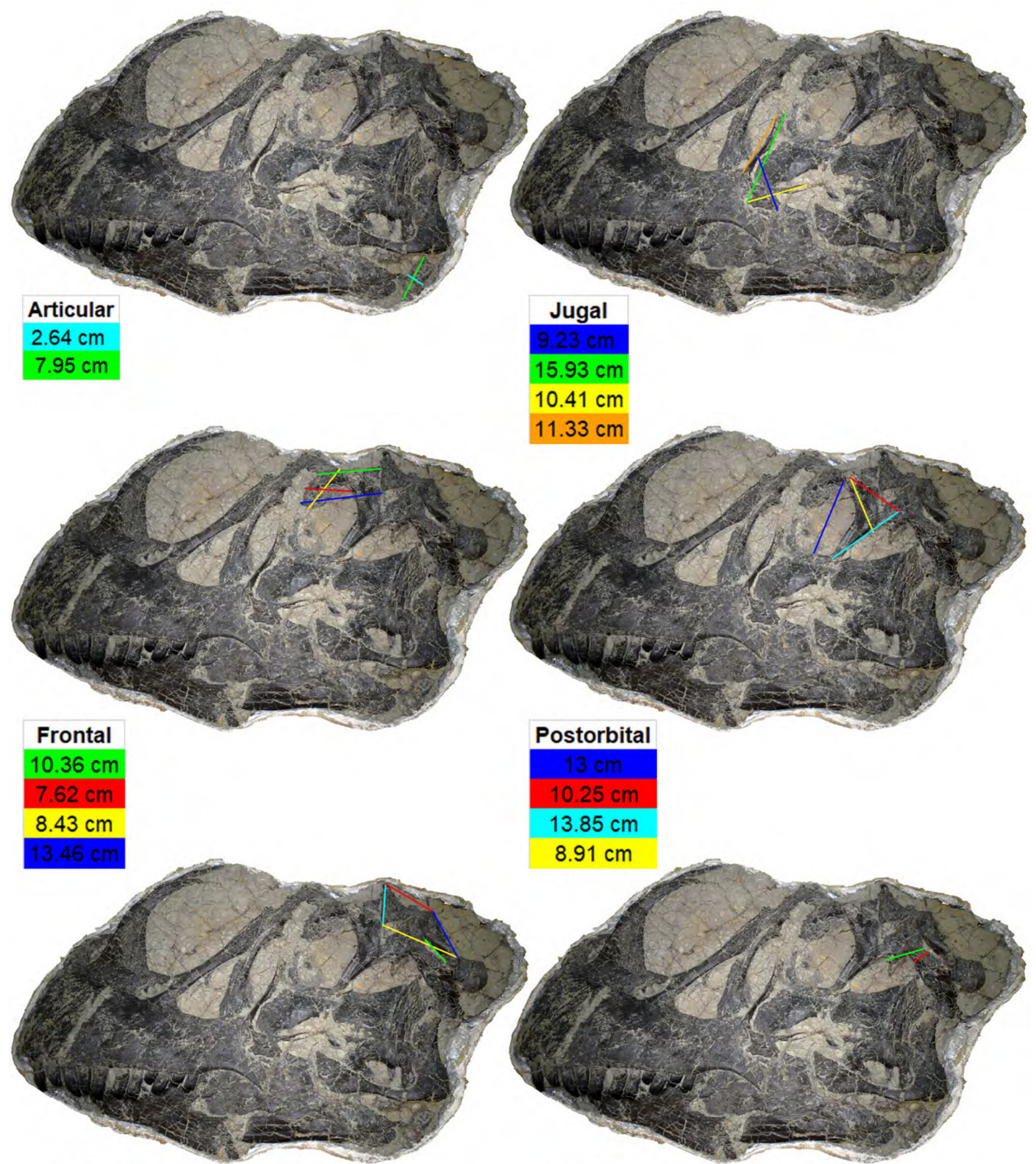

\section{Supraoccipital}

\section{Parietal}

$5.19 \mathrm{~cm}$

$6.92 \mathrm{~cm}$

$2.95 \mathrm{~cm}$

$13.79 \mathrm{~cm}$

$9.05 \mathrm{~cm}$ 


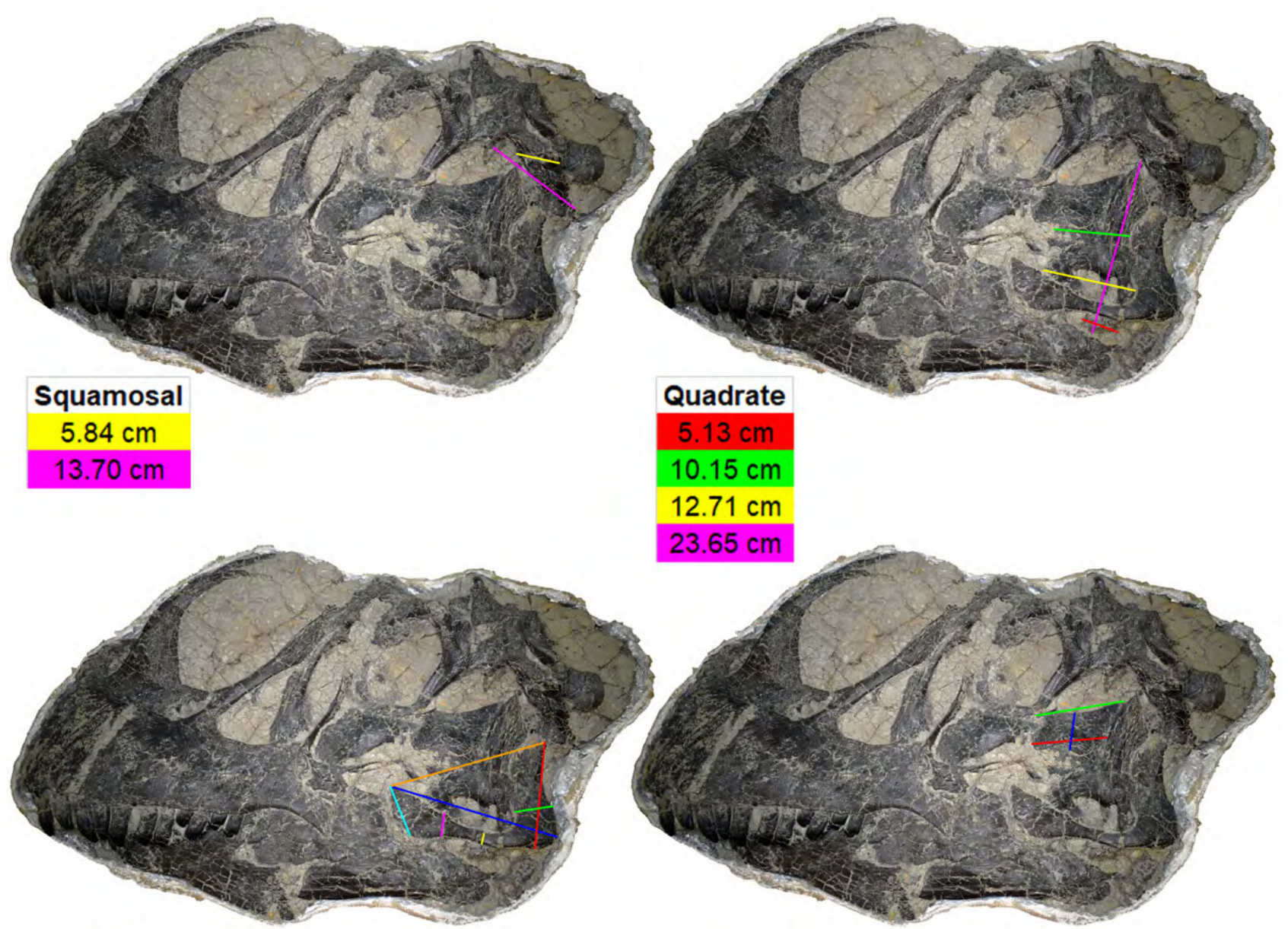

\begin{tabular}{|c|c|}
\hline Quadratojugal \\
\hline $2.99 \mathrm{~cm}$ & $14.25 \mathrm{~cm}$ \\
\hline $1.43 \mathrm{~cm}$ & $21.48 \mathrm{~cm}$ \\
\hline $5.20 \mathrm{~cm}$ & $23.33 \mathrm{~cm}$ \\
\hline $7.14 \mathrm{~cm}$ & \\
\hline
\end{tabular}
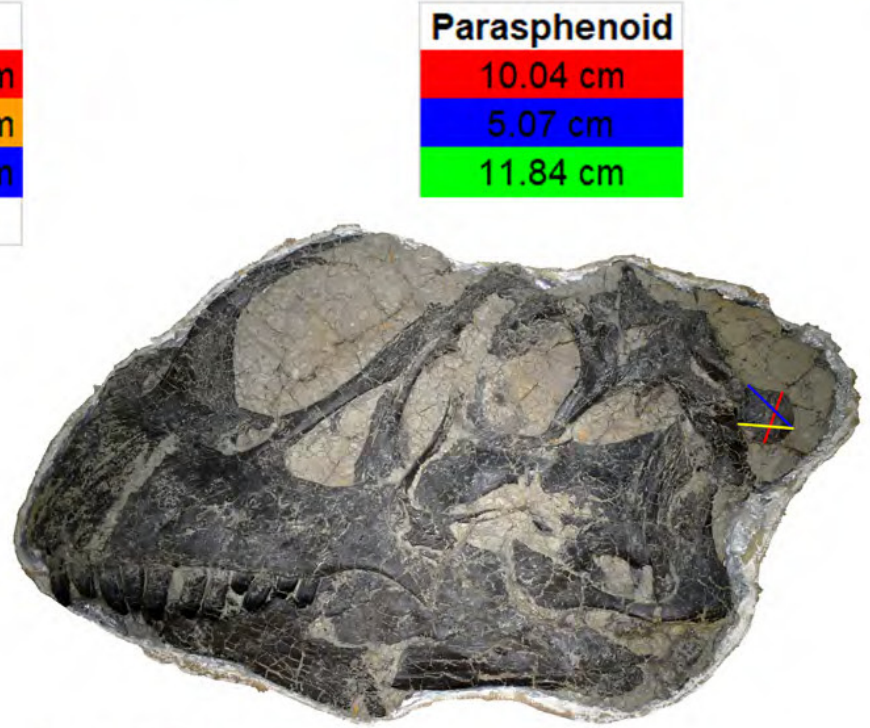

Occipital condyle

$5.56 \mathrm{~cm}$

$5.59 \mathrm{~cm}$ 
